María Teresa Viviani R.

Profesora del Instituto de Estética

Pontificia Universidad Católica de Chile

\title{
Comunidades cristianas al este del Jordán. Un análisis arquitectónico (S. I-VI D. C.)
}

\section{SITUACIÓN GEOGRÁFICA Y RUTAS CARAVANERAS}

En mi investigación "The Jordan River as a natural barrier between two expressions of Christianity. An architectural analysis. Palestine and Hawran (300-700 A.D.)" (1) propongo que el río Jordán actuó como una barrera natural que separó dos modalidades de cristianismo. Esta separación se debió a las características geográficas de la zona y ha significado a través del tiempo una real separación cultural entre un área vinculada y abierta al Mediterráneo y otra área que ha mirado más hacia el este y que ha estado influenciada por las antiguas y tradicionales culturas del Medio Oriente.

Las áreas precisas de difusión, en Transjordania, de la arquitectura romanocristiana propia de Palestina, nos permiten establecer, con mucha precisión, los límites y características de la penetración del Imperio Romano hacia el este del río.

El río Jordán nace en el Monte Hermón $(2.800 \mathrm{~m})$, el más alto de la región y comienza a descender (su nombre significa "el que desciende") hacia el sur por una falla geológica, llamada el Gran Rift, que desaparece en el Mar Rojo y aparece nuevamente en África. Como resultado de esta falla, en el Mar de Galilea el río ya alcanza una profundidad de $210 \mathrm{~m}$ bajo el nivel del mar, y en el Mar Muerto, donde desemboca y muere, el nivel del agua alcanza $410 \mathrm{~m}$ bajo el nivel del mar. En este lugar la depresión misma es de $740 \mathrm{~m}$.

En la Fig. 1 vemos una extraordinaria imagen satelital de la franja oriental del Mediterráneo, publicada por The National Geographic y podemos observar con gran claridad el curso que sigue el río Jordán desde el Monte Hermón, cruzando luego por el Mar de Galilea, hasta morir en el Mar Muerto. Se puede apreciar también en

(1) "The Jordan River as a natural barrier berween two expressions of Christianity. An architectural analysis. Palestine and Hawran (300-700 A.D.)", Ponencia presentada en el Aram Seventeeth International Conference: Palestinian Christianity, julio 2001, The Oriental Institute, Oxford University, England. Será publicada en ARAM periodical, vol. 15, Oxford University. 


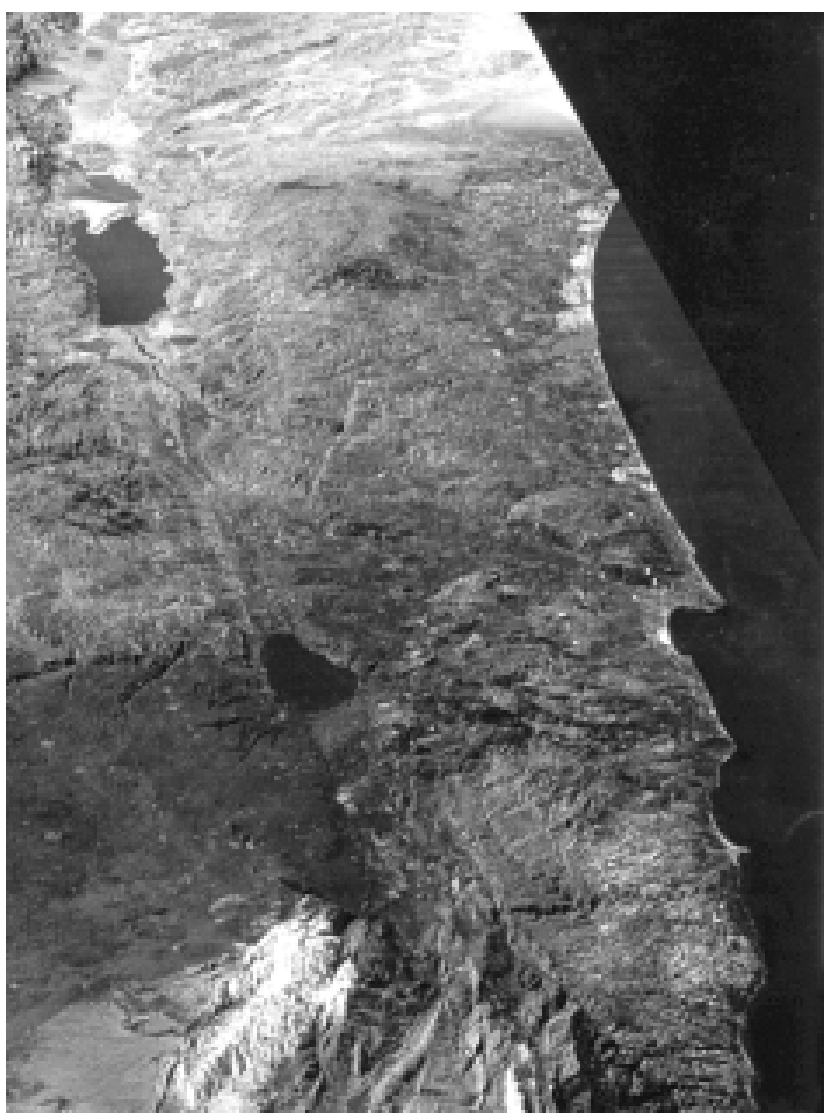

Figura 1: Imagen satelital del río Jordán y el Gran Rift, The National Geographic, 187/6 (June 1995).

forma panorámica, la profunda depresión geológica del Gran Rift, verdadera grieta en la corteza terrestre, por donde encauza el río, en forma natural, sus aguas.

En la Fig. 2 se pueden apreciar con más detalle algunas características geográficas de la región y las montañas que bordean el Gran Rift. Si sumamos a la depresión natural del terreno, la altura de las montañas del flanco este (1.000$1.200 \mathrm{~m})$, o del lado oeste $(800-1.000 \mathrm{~m})$, nos podemos dar cuenta de que el río corre por un cañón de cerca de $1.600 \mathrm{~m}$ de profundidad; esto dificulta el cruce de una ribera a la otra. A este obstáculo debemos agregar las altas temperaturas del verano $\left(40^{\circ}\right)$.

La zona es de gran belleza, pero su naturaleza es dura y áspera. El espacio más habitable y amable se encuentra en el norte, cerca del Mar de Galilea, paisaje familiar a Jesús y a sus discípulos. Hacia el sur el verde de los oasis lo encontramos sólo en pequeños fragmentos del paisaje.

Más hacia el sur del Mar Muerto y del río Jordán la depresión del Gran Rift continúa por el llamado Wadi (valle) Araba, hasta Aqaba y Eilat en el Mar Rojo. Esta región es extremadamente calurosa y seca, no apta para ningún tipo de cultivo agrícola ni pastoreo. Por el Wadi Musa, hacia la izquierda del Wadi Araba, se podía 


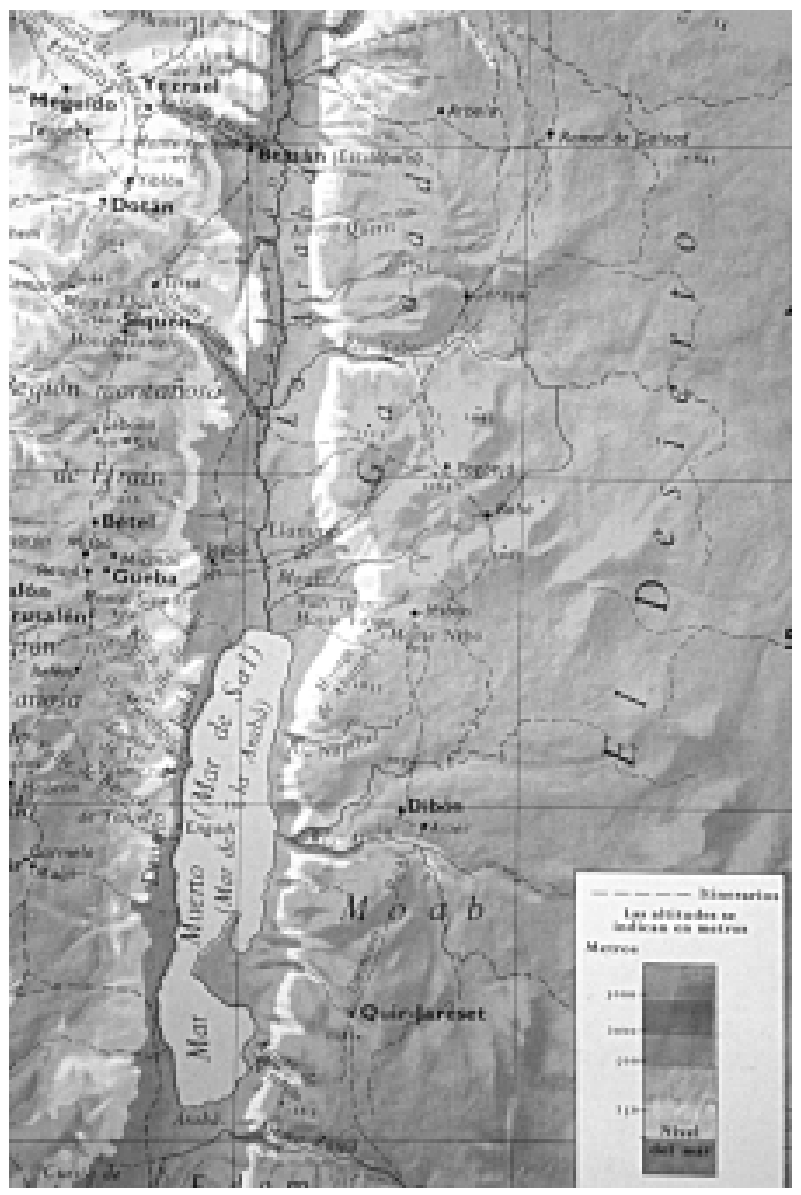

Figura 2: Altura de las colinas al este y oeste del valle del río Jordán, Atlas Bíblico Oxford, San Pablo, Madrid, 1998, p. 49.

acceder a Petra, cuya legendaria belleza se debe al brillo y colorido de la piedra calcárea del Gran Rift (2).

La actividad más importante al Este del Jordán, era el comercio de las caravanas. Se formaba un corredor natural en el eje norte-sur, con dos caminos principales, que pasaban por Bosra y Damasco, entre el Gran Rift y el desierto (ver Fig. 3). Estas rutas se conectaban con rutas transversales, en la dirección este-oeste, que salían a los puertos del Mediterráneo. Por el sur la región conectaba con la India, la baja Mesopotamia y Arabia; por el norte, empalmaban con los caminos procedentes de China y Persia, que pasaban por el norte de Mesopotamia y Siria (3).

(2) Para información de la región del Jordán desde un interés bíblico, ver Burton MacDonald, Chapter 3, "Natural Environment", East of the Jordan, Territories and Sites of the Hebrew Scripture, American Schools of Oriental Research, USA, 2000.

(3) Para información sobre las rutas caravaneras en el Medio Oriente, ver G. W. Bowersock, Roman Arabia, Massachussetts, 1983, y "Trade Routes in the Near East", ARAM Periodical, vol. 8:1 y 2 (1996), Oxford University. 


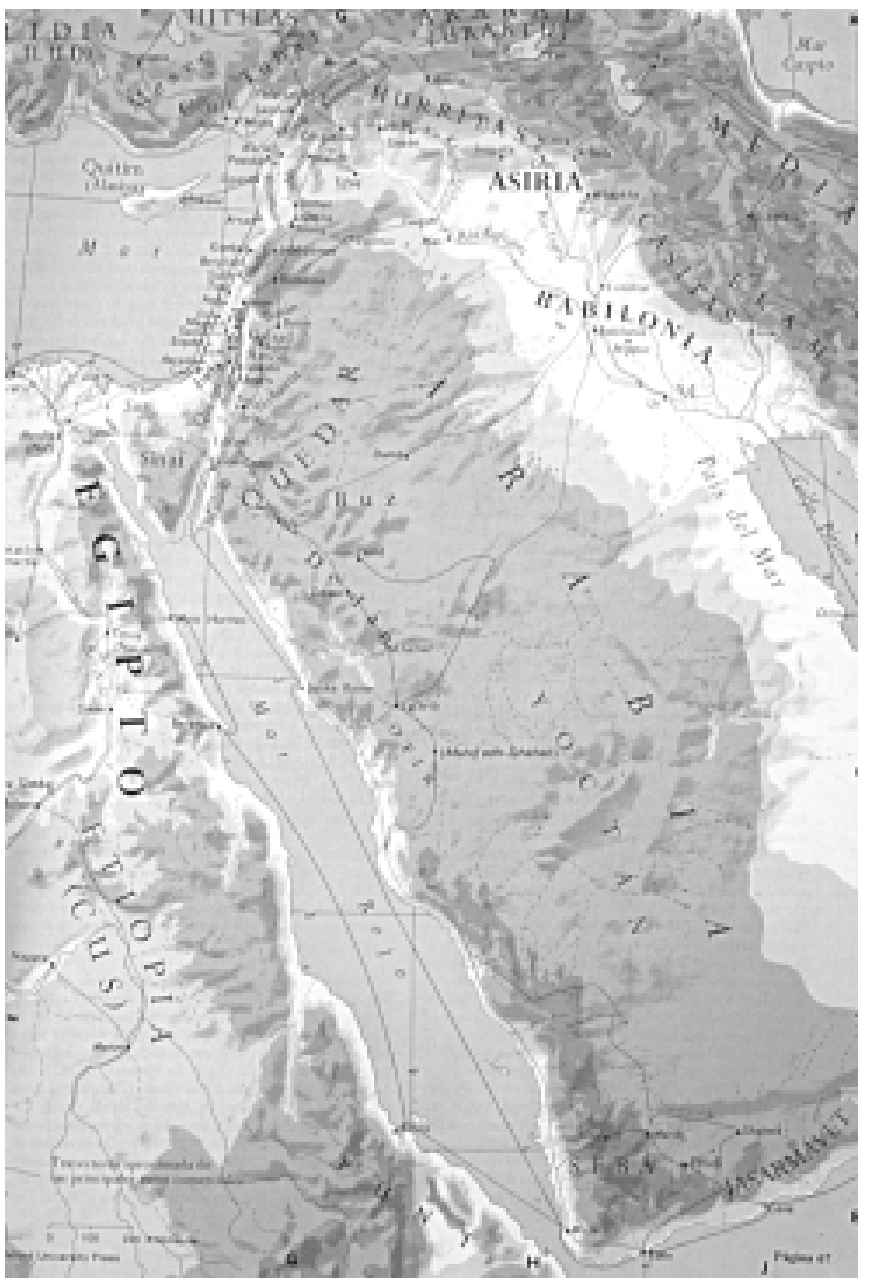

Figura 3: Ruta norte-sur al este del Jordán y conexiones transversales, Atlas Bíblico Oxford, San Pablo, Madrid, 1998 , p. 67.

Por el norte del Mar de Galilea cruzaba la Vía Maris que unía Damasco con el Mediterráneo y permitía sacar los productos hacia el mar. Este camino seguía hacia el sur por la costa de Palestina, pasaba por Gaza y finalmente llegaba a Alejandría, en Egipto.

Entre el Mar de Galilea y el Mar Muerto, el Wadi Yarmuk, el Wadi Yabook y el Wadi Mujib, facilitaban el cruce desde Palestina hacia la ribera este del río. Estos cruces fueron utilizados especialmente por griegos y romanos.

Al Sur del Mar Muerto, por Petra, cruzaba hacia el Mediterráneo la llamada Vía de las Especies o del Incienso. Esta ruta pasaba por el Desierto del Negev y llegaba hasta Gaza, donde empalmaba con la ruta de la costa de Palestina. Hacia el este, cruzando el desierto por Hira, el camino conectaba con la baja Mesopotamia.

Pequeñas aldeas, necesarias para sustentar esta forma de comercio, florecían cercanas a las rutas caravaneras. En cruces estratégicos surgían importantes mercados, ferias y santuarios religiosos. 
La explotación y tráfico de las caravanas por el desierto era casi impensable sin el uso del camello. Además de su conocida capacidad para recorrer grandes distancias, en un clima muy caluroso y con un mínimo de agua, cada camello era capaz de transportar entre 150 y $200 \mathrm{~kg}$. En Arabia se dice que existían caravanas que tenían más de 1.000 camellos, lo que significa una extraordinaria capacidad total de carga.

En Arabia se conoce el uso del camello con fines de carga ya en el año 1.000 A. C., y algunos autores sostienen que sería originario de esta zona (4). Tras su cuidado existía un verdadero profesionalismo, dedicación y cariño. Un camello es para un beduino un verdadero tesoro y su uso en el desierto es muy apreciado y necesario hasta el día de hoy.

Parece interesante destacar que el tráfico de las caravanas no solo significa intercambio de productos, sino también un permanente flujo de influencias culturales; se trata de miles de personas que están en permanente movimiento y junto con ellos se moviliza su religión, el arte, el lenguaje, las tradiciones.

En estos pueblos en donde prima la acción y una vida en permanente desplazamiento por el territorio, la identidad y sentido de pertenencia, se desarrolla ligada a los vínculos familiares y tribales, a las jerarquías y lazos sociales, a los códigos de honor, más que unida a un determinado espacio físico, una ciudad o una propiedad privada.

\section{TRANSJORDANIA, ESPACIO DE “CARGA MÍTICA NEGATIVA”}

Desde la perspectiva de la tradición bíblica, la Transjordania o tierras al este del Jordán, va adquiriendo a lo largo de la historia, una "carga mítica de sentido negativo". Los textos bíblicos han sido escritos con fines religiosos y nacionalistas y no con fines históricos, pero de todas maneras es una forma de hacer historia y el lenguaje va creando realidad y va cargando con un especial sentido los territorios, los personajes, los acontecimientos.

Tratándose de las tierras del este los autores que escriben al respecto viven la mayor parte del tiempo en Cisjordania, en el lado occidental del Jordán, y solo ven la Transjordania desde lejos, a través del río, pero sin tener un conocimiento personal de la región ni de su gente.

B. MacDonald (5) dice: "ellos escribían sobre el área de una manera prejuiciada, como la tierra de sus enemigos. Un gran número de textos describen la Transjordania como, histórica, geográfica e ideológicamente extraña" (pp.19-20). Todo lo nefasto, lo distinto e inquietante, a veces también atractivo, ocurría al otro lado del Jordán, en las tierras del oriente. La región del este fue así una zona distinta, poco conocida, y por esta misma razón, incomprensible y amenazante, míticamente negativa. Todo esto es lo que deseo expresar cuando hablo de una tierra con una "carga mítica negativa". Este sentir negativo dificulta y distorsiona, hasta el día de hoy, los estudios del área.

(4) Sobre el origen y uso del camello en el Medio Oriente, ver I. Köhler-Rollefson, "Camels and camel. Pastoralism in Arabia", Biblical Archaeologist 56:4, (1993), pp. 180-188.

Ver cita 2 . 
Nombraré a continuación, a modo de ejemplo, algunos hechos que acontecen en Transjordania y que están teñidos de un sentir negativo.

Los israelitas, para avanzar desde el Sinaí y el Mar Rojo hacia el norte y la Tierra Prometida, debían seguir la ruta normal de Transjordania, el "Camino Real" o "King Highway" citado en la Biblia. Este camino corría paralelo al Wadi Araba (ver Fig. 4). En este avance hacia el norte ellos van encontrando una oposición y obstáculos, una competencia, en los pueblos del este del Jordán que ocupan la zona.

En la ribera sur-este del Mar Muerto o Mar de Sal, se cree que se encontraban las 5 ciudades del valle de Sidim asociadas a Lot y a su familia (6): Sodoma, Gomorra, Admá, Zeboyim y Belá (Soar) (ver Fig. 5).

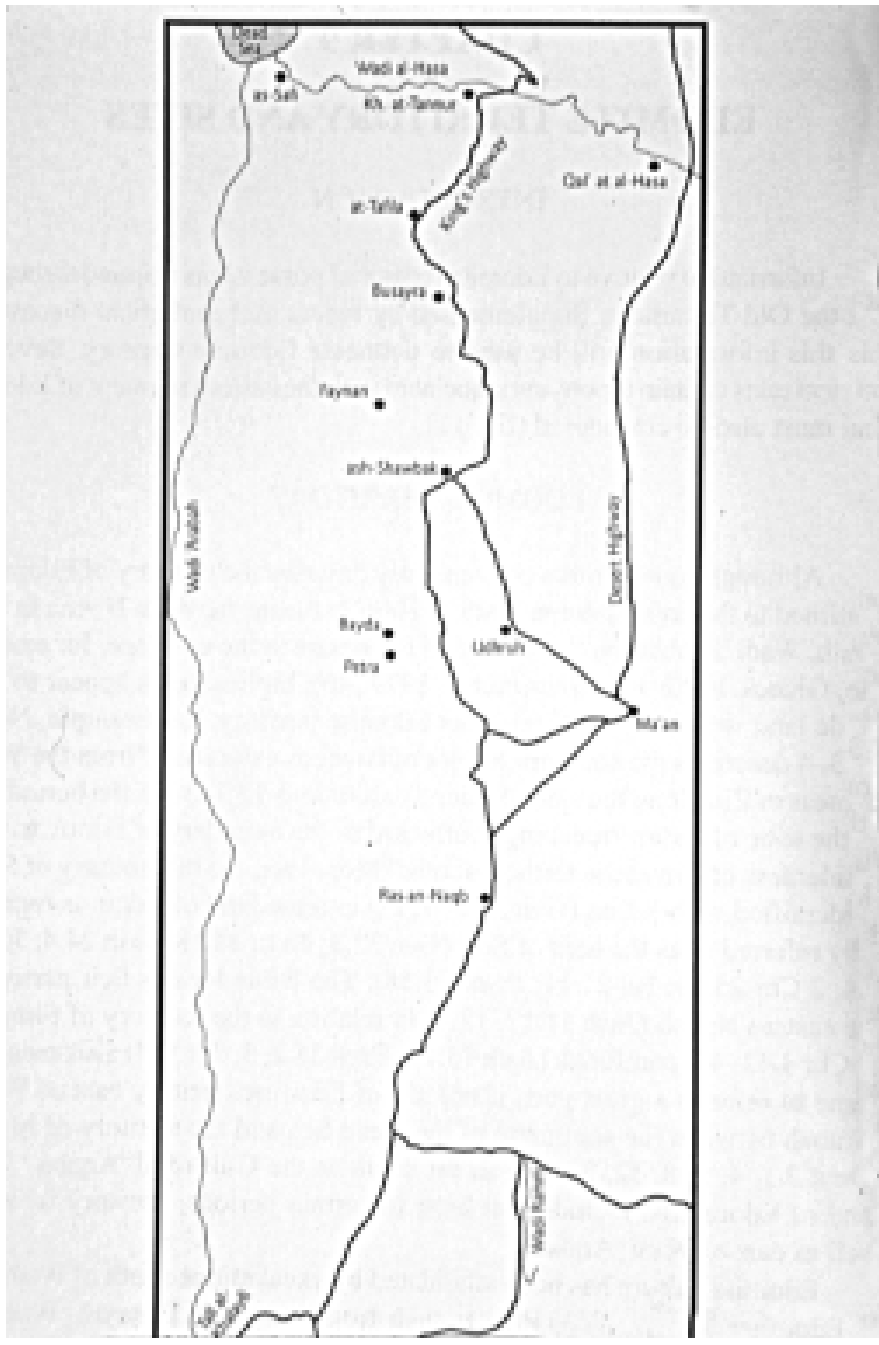

Figura 4: Camino Real y Camino del Desierto, B. MacDonald, East of the Jordan, American Schools of Oriental Research, USA, 2000, p. 186. 


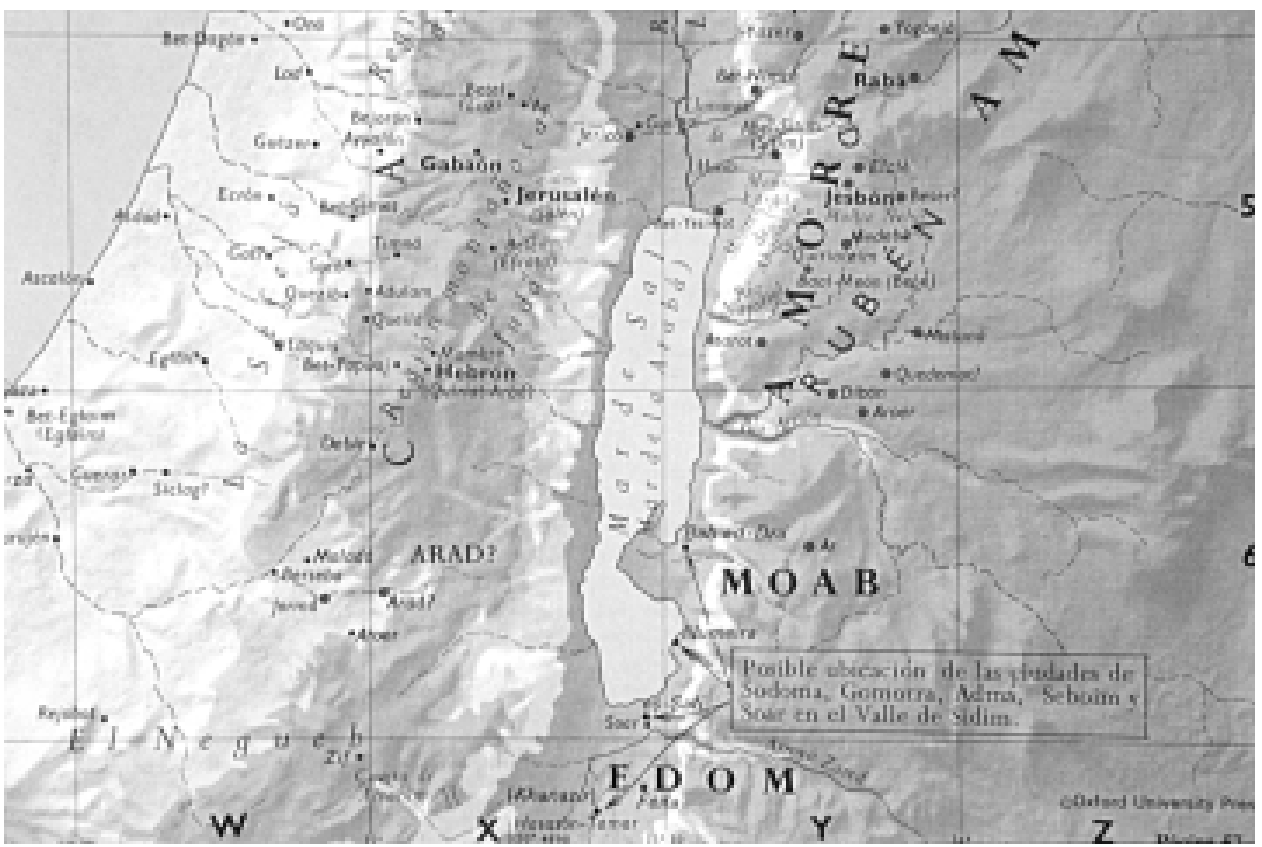

Figura 5: Cinco ciudades en el valle de Sidim, Atlas Bíblico Oxford, San Pablo, Madrid, 1998, p. 57.

La tradición recuerda que bajo el Mar Muerto, en el lugar de las salinas, existe una columna de sal desde los tiempos de la historia de la mujer de Lot, que sería visible dependiendo del nivel del agua del lago. La historia cuenta también que Lot y sus dos hijas, huyendo de la destrucción de Sodoma y Gomorra, se habrían refugiado en una cueva cerca de Soar. Aquí habrían nacido, de una unión incestuosa, Moab, padre de los Moabitas y Ben-Ammí, padre de los Amonitas (7).

En la historia de Moisés encontramos también muchos recuerdos tristes y negativos asociados al este del Jordán. En su avance hacia la Tierra Prometida, se tiene que enfrentar en la Transjordania con Edomitas, Amorreos, Amonitas, Moabitas (con sus mujeres pecadoras), Además, él mismo está condenado a morir al este del Jordán, en el Monte Nebo, como castigo de Yahvéh. No podrá cruzar el Jordán y solo tendrá permitido observar la Tierra Prometida desde lejos.

Le dice Yahvéh a Moisés:

"Sube a esa montaña de los Abarin, al Monte Nebo que está en el país de Moab, frente a Jericó, y contempla la tierra de Canaán que yo doy en propiedad a los hijos de Israel. En el Monte que vas a subir morirás, y te irás a reunir con los tuyos, como tu hermano Aarón..." (8).

(7) Gn., 19: 30-38

(8) Dt., 32: 48-52. 
La Tierra Prometida, en contraste con las tierras de Transjordania, pobladas por pueblos hostiles y mujeres de mala vida, se ofrece como un verdadero oasis y paraíso:

"Tierra de torrentes y de fuentes, de aguas que brotan del abismo en los valles y en las montañas, tierra de trigo y de cebada, de viñas, higueras y granados, tierra de olivares, de aceite y de miel, tierra donde el pan que comas no te será racionado y donde no carecerás de nada; tierra donde las piedras tienen hierro y de cuyas montañas extraerás el bronce" (14).

En la Transjordania, en las tierras de los Moabitas, se instalan las tribus de Moisés que no desean cruzar hacia el oeste del río: la tribu de Rubén, de Gad y la media tribu de Manasés. Esta actitud suscita desagrado en Moisés:

“¿Por qué estorbáis a los hijos de Israel de pasar a la tierra que les ha dado Yahvéh? Así hicieron ya vuestros padres, cuando los mandé de Cadés-Barnea a ver la tierra... ¡Y ahora vosotros os alzáis a imitación de vuestros padres, como retoño de hombres pecadores, para atizar más el fuego de la ira de Yahvéh contra Israel!" (10).

Moisés establecerá tres ciudades al Este del Jordán para el asilo y refugio de los homicidas. Leemos en Deuteronomio:

"Moisés reservó entonces tres ciudades allende el Jordán, al oriente, en las que encontrará asilo el homicida que hubiera matado a su prójimo sin querer, sin haberle odiado anteriormente, y refugiándose en una de estas ciudades, salvará su vida" (11).

En la historia de David encontramos también importantes testimonios de conflictos en las tierras del este. Luchará contra los Arameos y los Amonitas (12) y más simbólico aún, enviará a luchar contra los Amonitas a Urías, el hitita, marido de Betsabé. Urías, como era esperado, muere en el frente de batalla, reforzando estas tierras con historias nefastas y negativas. Dice el texto:

"Escribió David una carta a Joab y se la envió por medio de Urías. En la carta había escrito: 'Poned a Urías frente a lo más reñido de la batalla y retiraos de detrás de él para que sea herido y muera... y murió también Urías el hitita” (13).

En el período de la helenización del Medio Oriente, primero los Ptolomeos, y posteriormente los Seléucidas, intentaron controlar e instalarse en la región, pero sin

(9) Dt., 8: 7-10.

(10) Nm., 32: 6-15.

(11) Dt., 4: 41-43.

(12) 2 S., 10:6-19.

(13) 2 S., 11:14-17 
éxito. El clima y la geografía, el idioma, la forma de vida mayoritariamente nómade de sus habitantes, hacía difícil mantener ciudades o guarniciones permanentes. Para ellos era más simple cruzar todo el Mediterráneo navegando, que avanzar hacia el interior del desierto.

Los romanos quisieron también ocupar la zona. Construyeron guarniciones fronterizas, pero estas fueron finalmente atendidas por población local árabe. Construyeron la Via Nova Traiana y la Via Nova Diocletiana, para hacer más expedita la unión del Mar Rojo con Bosra y Damasco y facilitar el movimiento de sus tropas y la defensa de la frontera, pero, como lo explica G. W. Bowersock, sirvieron mejor al propio tráfico caravanero que a fines defensivos (ver Fig. 6).

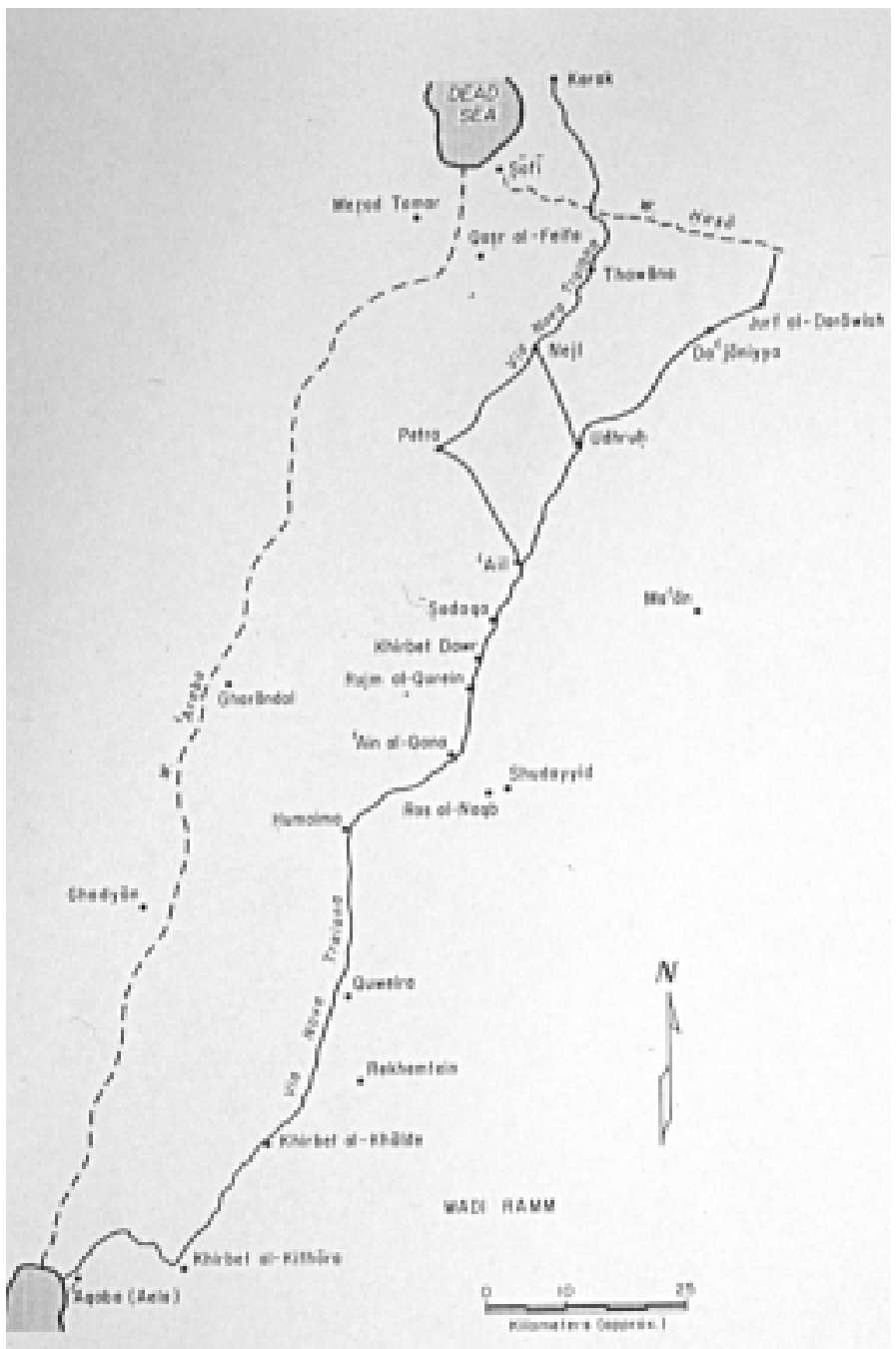

Figura 6: Via Nova Traiana, G. W. Bowersock, Roman Arabia, Massachussetts, 1983, p. 93. 
Los romanos terminaron pactando con los jefes de las tribus beduinas, philarcas, la defensa de las fronteras con los persas y con las tribus hostiles del desierto. Esto les significó a las tribus recibir el pago de un tributo y la garantía de vivir en paz, con lo cual la población local no alteró en gran manera sus normales actividades, ni vivió sujeta a las vicisitudes propias del Imperio (14).

Desde el S. IV A. C., el área fue controlada por los Nabateos con su capital en Petra. El año 105 D. C., los Nabateos fueron derrotados por los romanos y la región fue transformada en Provincia romana, pero esta nueva distribución administrativa no cambió mucho la vida en la zona. De hecho, en este momento, el control lo empezaron a tener los palmiranos, con su capital en el norte, en Palmira. La famosa reina Zenobia, una segunda Cleopatra, extendió peligrosamente sus dominios hasta Egipto.

El año 272, los romanos destruyeron el poderoso reino de Palmira y pactaron con las tribus Láchmidas, con su capital en Hira (camino hacia la baja Mesopotamia por el Sur), el control de la región. El último rey Láchmida fue Mundir, quien muere en la batalla de Chalcis en mano de los Ghassánidas, quienes mantendrán desde este momento el control de la región, hasta la llegada de los musulmanes. Los Ghassánidas tienen su capital en el norte cerca del Golán (15).

Como conclusión, se podría decir que el freno y límite de la expansión del Imperio Romano hacia el este, lo marcó el río Jordán y la población tribal que vivía en las áreas orientales del río. El Jordán estableció una barrera natural, que ha seguido ejerciendo influencias en la región hasta el día de hoy.

En los primeros siglos del cristianismo, las tierras del este se transformaron en lugar de destierro y exilio, también de autoexilio y refugio para los perseguidos por conflictos políticos o religiosos. Los primeros testimonios los tenemos de un grupo de cristianos de Jerusalén que huyen a Pella en el año 70. Otro grupo de cristianos, en el S. III, busca refugio en Transjordania para protegerse de las persecuciones de Decio. Nestorio y Flaviano de Antioquía fueron exiliados a Petra y Elía de Judea en Aqaba. Tanto los monofisitas de Palestina que huyeron de los ortodoxos, como los monjes ortodoxos, que en otros momentos debieron huir de los origenistas, buscaron también refugio en la Transjordania.

El Emperador Justiniano, en el S. VI, no deja de perseguir a los samaritanos y a los judíos, hasta que los expulsa más allá del río Jordán. Durante la devastadora invasión persa (614-627 D. C.), mucha población se protege cruzando el valle del Jordán hacia el este, aprovechando que la región queda marginada del pasillo natural que se forma al norte de Mesopotamia, por donde se movilizaban tanto los romanos como los persas.

En los escritos de Eusebio de Cesarea, encontramos algunos datos concretos de la percepción negativa que tenían los romanos de las poblaciones del este o del oriente. En La Vida de Constantino leemos:

"El Imperio Romano en su conjunto parecía dividido en dos secciones, semejándose una al día, a la noche la otra; la oscuridad sobrenadaba a los que les

(14) Sobre acuerdos y pactos de los romanos con las tribus de Transjordania, ver G. W. Bowersock, Roman Arabia, Massachussetts, 1983.

(15) Sobre el control Ghassánida en Transjordania, ver I. Shaid, "The restoration of the Ghassanid dynasty", ARAM Periodical, 5 (1993), Oxford, pp. 491-503. 
cupo en suerte habitar el Oriente, inversamente, un día radiante refulgía sobre los del otro sector" (16).

Más adelante, Eusebio agrega:

"Los bárbaros que en aquellas circunstancias acogieron a nuestros tránsfugas y los protegieron con benevolente cautividad, andan jactándose de que no solo garantizaron su seguridad personal, sino que permitióseles celebrar sus ritos a recaudo. Actualmente, el pueblo romano está soportando esa persistente mácula que los cristianos expulsados por aquel tiempo de la población romana y huidos tras las fronteras bárbaras le dejaron estampada" (17).

El sentido negativo con que se percibía desde occidente las tierras del oriente bárbaro, como lugar de lo nefasto y de lo desconocido, de lo inhóspito y distinto, como lugar de exilio y destierro, forzado o voluntario, se mantuvo hasta la llegada del Islam. A los ojos del Imperio Romano era una zona marginal, pobre, poco atractiva, en donde se vivían las consecuencias de la soledad y aislamiento.

Me parece que la lectura negativa que ha hecho occidente de la historia de las comunidades del este, es solo una cuestión de perspectiva y dificulta, hasta el día de hoy, nuestro estudio y comprensión de la región. Los autores que están tratando de releer la historia, acusan la dificultad que significa tener como única fuente de estudio textos que, como el que acabamos de citar, reflejan esta visión que llamo de "carga mítica negativa".

Las comunidades cristianas de la Transjordania, evangelizadas desde tiempos muy tempranos, pudieron conciliar su forma de vida con la nueva religión y supieron defender su territorio e identidad de cualquier intromisión foránea, sin un quiebre con sus valores centrales ni con la tradición.

\section{4 TIPOS DE COMUNIDADES}

\section{A) Las ciudades de la Decápolis}

Se llamó Decápolis a un grupo de ciudades helenizadas, al norte de Palestina y Transjordania. No hay que pensar que realmente eran 10 ciudades, sino que es el nombre con que se las reconoce, nombre dado por los romanos.

En su mayoría, son ciudades de origen Nabateo, ocupadas y helenizadas primero por los ptolomeos, luego por los seléucidas y finalmente por los romanos. Los romanos las ampliaron e integraron nuevas ciudades al conjunto. Su principal función era servir de defensa para el paso de las tribus del este hacia Palestina. Tenían, como una típica ciudad griega, templos paganos, edificios administrativos, teatros y por lo general, instalaciones defensivas (ver Fig. 7).

(16) Eusebio de Cesarea, Vida de Constantino, Libro I, 49, Gredos, Madrid, 1994, p. 193.

(17) Eusebio de Cesarea, Vida de Constantino, Libro II, 53, Gredos, Madrid, 1994, p. 244. 


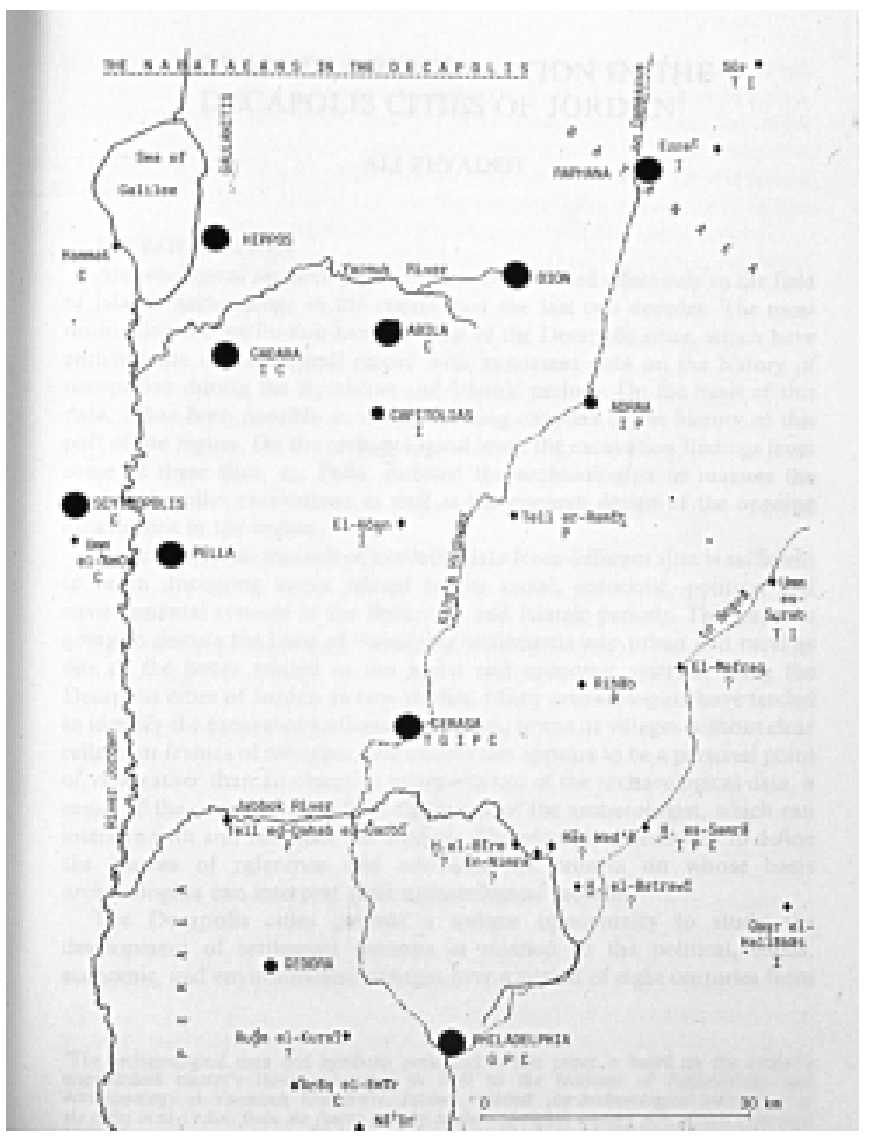

Figura 7: Ciudades Nabateas de la Decápolis, "The Nabateans in the Decapolis/Coele Syria", ARAM 4 (1992), The Decapolis, Oxford, p. 99.

No necesariamente la helenización de la Decápolis significó la helenización de la población rural. Al igual que en la ocupación romana de Palestina, el control e influencia del Imperio se ejerció solo de ciudad en ciudad. Hoy se ha demostrado que la población rural siguió manteniendo sus costumbres y lengua vernácula y que las áreas rurales sirvieron de refugio para muchos monjes y disidentes del poder central. La naturaleza montañosa y desértica facilitó este modo peculiar de compartir el territorio.

Las ciudades de la Decápolis que están al este del Jordán se encuentran en la región que ya he señalado, de fácil acceso por los Wadis Yarmuk, Yabbok y Mujib, al sur del Mar de Galilea.

En esta oportunidad no trataré en forma extensa las comunidades cristianas de la Decápolis, ya que es un tema que he trabajado en el artículo "The Jordan River as a natural barrier between two expresión of Christianitty ..." (18). Su cristianismo y arquitectura siguen los vaivenes y características del Imperio y del cristianismo palestino. 
En las ciudades de la Decápolis se construyeron basílicas cristianas a partir del siglo VI D. C.; reúnen todas las características de las basílicas palestinas. Son construcciones que representan una continuidad con las normas establecidas para el Imperio, ya desde tiempos de Constantino. En términos muy actuales, se podría decir que se insertan dentro de una "globalización estilística" muy bien manejada desde el poder central del Imperio. Reflejan las necesidades y protocolo de la iglesia oficial (ver Fig. 8).

Me parece más interesante destacar el hecho de Jesús trabajando como constructor (tekton), en la remodelación de la ciudad helenizada de Sepphoris, cerca de Nazaret, realizada por Herodes Antipas (18-26 D. C.). Aquí se cree que habría aprendido griego (19). Este dato es muy valioso para comprender la importancia que adquiere la arquitectura en los Evangelios y podría explicar la familiaridad con que Jesús construye metáforas y analogías entre el cuerpo, la comunidad, la arquitectura y el templo, utilizando términos propios del lenguaje arquitectónico (20).

\section{B) Los Monjes}

En los flancos orientales del Jordán (ver Fig. 9), al igual que en la ribera occidental, existían una gran cantidad de monjes, algunos viviendo en las llamadas

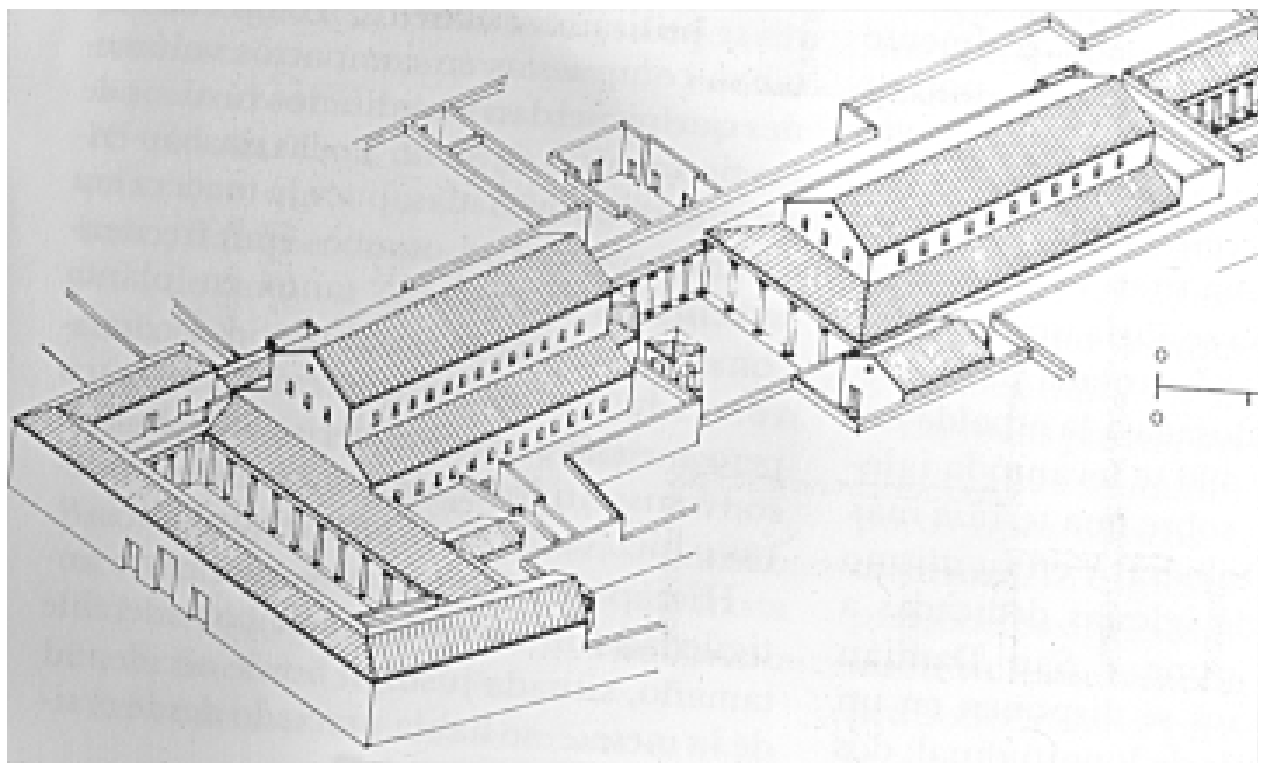

Figura 8: Reconstrucción isométrica de basílica de Gerasa, ciudad de la Decápolis, R. Krautheimer, Arquitectura Paleocristiana y Bizantina, Cátedra, Madrid, 1984, p.187.

(19) Sobre Jesús en Sepphoris, ver J. González Echegaray, VI, "Sepphoris y Jesús”, Jesús en Galilea, Aproximación desde la arqueología, Navarra, 2000, pp. 121-152.

(20) Para algunos datos sobre la construcción metafórica del templo, ver M. T. Viviani, "De la Casa Cristiana a la Basílica de Constantino”, Seminarios de Filosofía, Volumen Especial, 1993, pp. 117-133. 


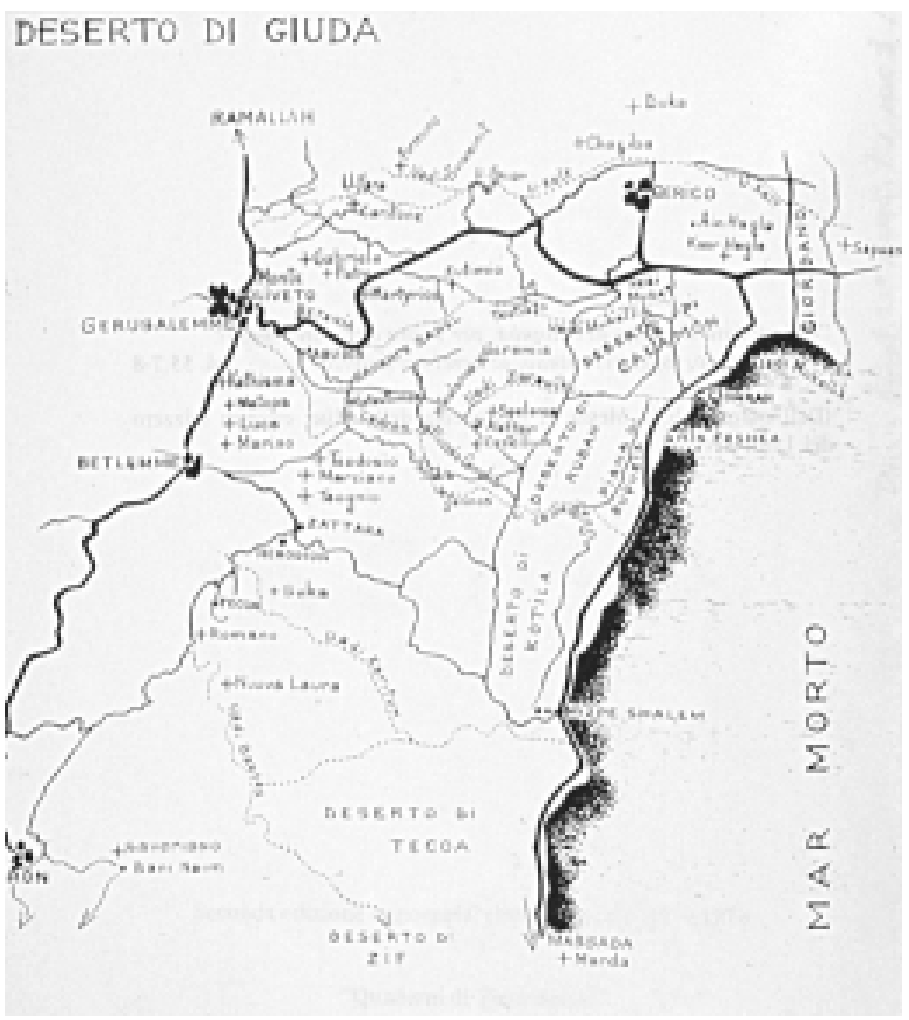

Figura 9: Monasterios y lauras entre el Mar Muerto y Jerusalén, P. Compagnoni, Deserto di Giuda, (Jerusalem, 1978), p. 6.

"Lauras", otros como solitarios, en celdas hechas al interior de la montaña. Había también muchos monasterios más complejos y estructurados (21).

No tengo plantas de capillas de monasterios o de lauras de esta región, pero sin duda respondían a la típica planta llamada monástica, utilizada en Palestina, de una sola nave y pequeña y que solo servía a las necesidades de los propios monjes (ver Figs. 10 y 11).

Las regiones más pobladas por los monjes estaban cerca del Monte Nebo y de Perea, donde la tradición recordaba que bautizaba San Juan Bautista. Jesús habría sido bautizado en la región de Perea, cerca de Jericó. Un camino paralelo al río, por su lado oriental, permitía desplazarse con mayor facilidad que por las montañas del oeste, desde el Mar de Galilea hasta Jericó.

Egeria, peregrina venida posiblemente de España y que recorre el Medio Oriente (381-384 D. C.), nos ha dejado importantes testimonios de los monjes de la zona. Visita el “Jardín Sagrado de Juan”, donde los monjes recordaban que había bautizado Juan. Está también en el Monte Nebo y la tumba de Jacob. Los amables monjes la acompañan en su peregrinación, mostrándole los santos lugares. Escribe en su diario, cuando va de viaje al Monte Nebo:

(21) Para información sobre los monasterios y lauras al oeste del Jordán, ver P. Compagnoni, Deserto di Giuda, Franciscan Printing Press, Jerusalem, 1978. 


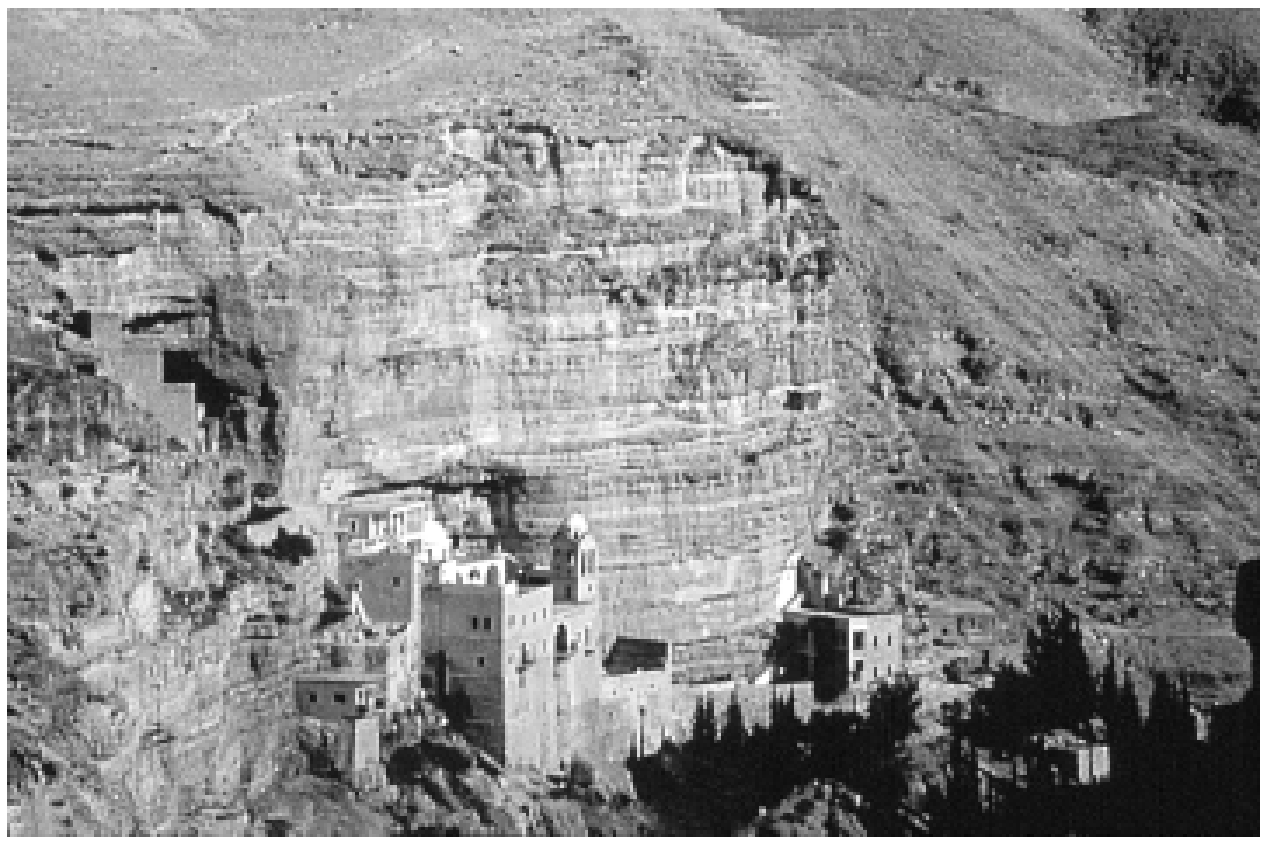

Figura 10: Monasterio de San Jorge, desierto de Judea, en uso desde el S. V, Shai Ginott Edit., Könemann, Cologne, 1999, p. 59.

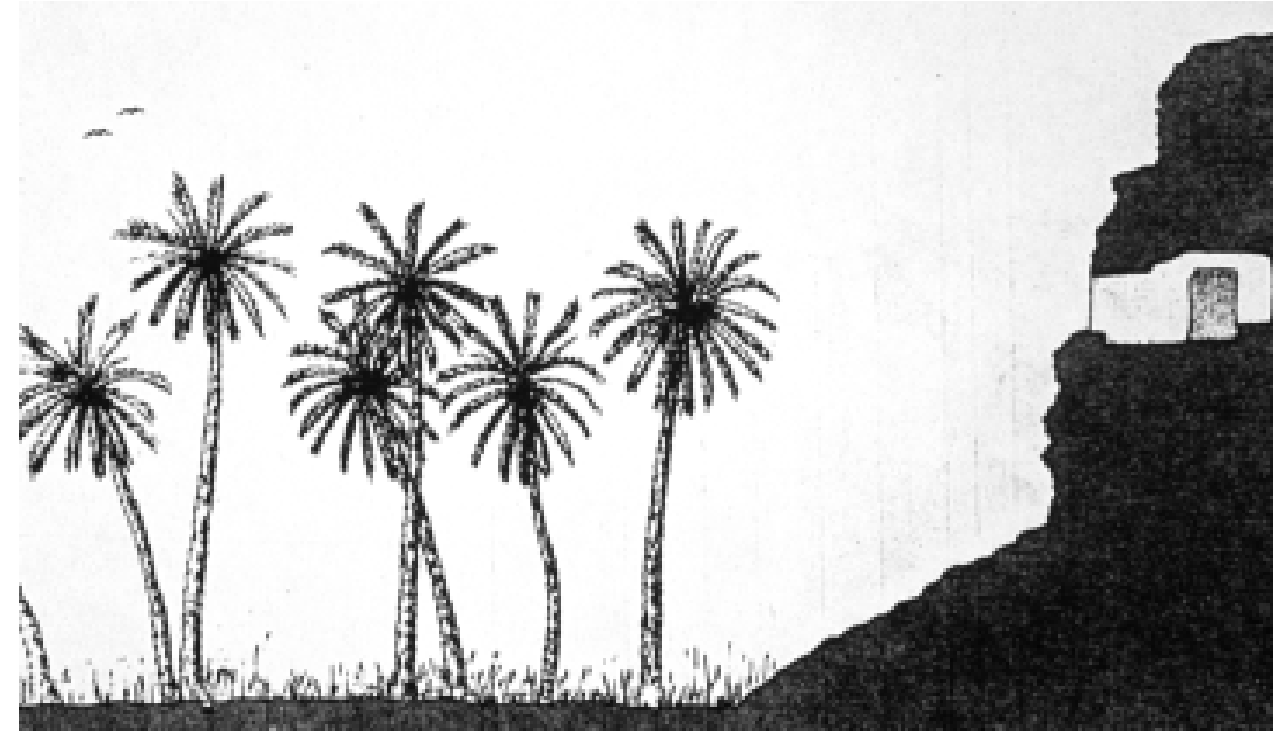

Figura 11: Capilla en laura de Gerasimus, valle del Jordán, Y. Hirschfeld, "Gerasimus and his laura in the Jordan Valley", Revue Biblique, 1991, 98-3, pp. 419-430. 
"En aquel lugar hay una iglesia pequeñita al pie del monte. No me refiero al monte Nebo sino a otro más adentro, no lejos del Nebo. Moran allí muchos monjes verdaderamente santos, que llaman ascetas. Estos santos monjes se dignaron recibirnos muy bondadosamente permitiéndonos entrar a saludarlos. Ya dentro, hicimos oración con ellos" (22).

Después de regresar de su viaje al Monte Nebo y estar un tiempo en Jerusalén, Egeria decide volver a Transjordania a visitar la tumba de Job. En la historia de este viaje hace alusión nuevamente a los monjes de la región:

"Pasado algún tiempo quise ir también a la región de Ausitis, para ver el sepulcro de Job y orar allí. Veía yo que muchos santos monjes venían de aquel lugar a visitar Jerusalén y orar en los santos lugares. Ellos me contaban todo lo referente a los santos lugares de donde venían, con lo cual se me encendían los deseos de imponerme la molestia de ir a visitarlos; ...así pues, salí de Jerusalén con aquellos santos que se dignaron acompañarme en el viaje;" (23).

Poco se conoce de estos monjes, pero en el lado occidental, donde se está estudiando mucho el movimiento monástico, la mayoría de las lauras o monasterios eran monofisitas. Se sabe de un monasterio nestoriano cerca de Jericó. En períodos más tardíos algunos monasterios se suman a la ortodoxia imperial.

En relación a los monjes, la arquitectura de Palestina testimonia una paradoja: por una parte, la gran ciudad estuvo dominada por la religiosidad e ideología del imperio y florecen allí las características basílicas. Por otra, en sus alrededores y en las áreas rurales, se instalaron los monjes, la mayoría de las veces en un claro antagonismo con la forma de religiosidad oficial que caracterizaba la ciudad.

Pienso que en Transjordania, que sirvió de asilo a mucha y variada población, los monjes siguen más o menos estos mismos comportamientos de rechazo al poder hegemónico central. La diferencia la encontramos en que en Transjordania los monjes fueron muy queridos y aceptados por las comunidades.

\section{C) Las comunidades del Haurán}

Las comunidades cristianas del Haurán están instaladas más hacia el este de las ciudades de la Decápolis, en una meseta volcánica llamada "Desierto Negro". Esta meseta, con una altura de $1.000 \mathrm{~m}$, es adecuada para la agricultura, lo que propició el asentamiento de numerosas aldeas, la mayoría de ellas de origen Nabateo. Era también una zona vecina a un centro neurálgico de cruce de las rutas caravaneras (ver Fig. 12 y 13).

Lo más interesante y propio que me interesa destacar de las comunidades del Haurán es la notable influencia de la arquitectura vernácula.

(22) T. H. Martin-Lunas Edit., Peregrinación de Egeria, Sígueme, Salamanca, 1994, p. 47.

(23) O.C., p. 50. 


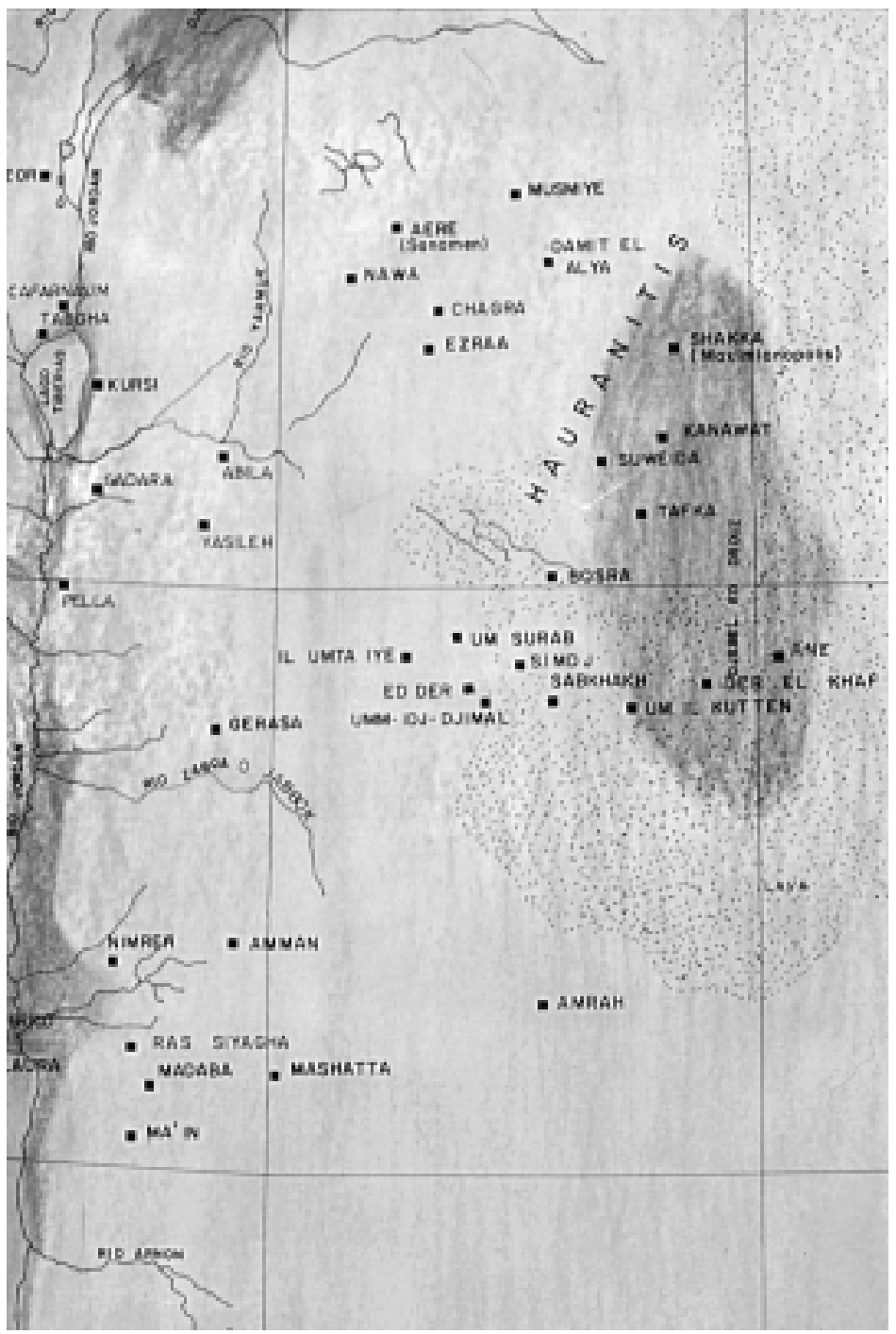

Figura 12: Aldeas del Haurán con plantas de iglesias, M. T. Viviani, Semiótica y Estética: Arquitectura Cristiana Mesoriental (S. I-V), Tesis de Grado, P. Universidad Católica de Chile, 1987.

En mi estudio "La fuerza de lo vernáculo en la arquitectura cristiana del Medio Oriente (S. IV-V)" (24), propongo que en el Medio Oriente, en la medida que uno se aleja de las zonas en donde el Imperio Romano ejerció un real control, las comunidades cristianas construyeron sus iglesias de acuerdo a las características de la arquitectura vernácula. Aquí desaparecen las típicas basílicas cristianas que identifican la presencia del Imperio. Los materiales, los métodos de construcción, la articu-

(24) M. T. Viviani, "La fuerza de lo vernáculo en la arquitectura cristiana del Medio Oriente (S. IVV)”, Teología y Vida, Vol. XXXIX (1998), pp. 398-415. 


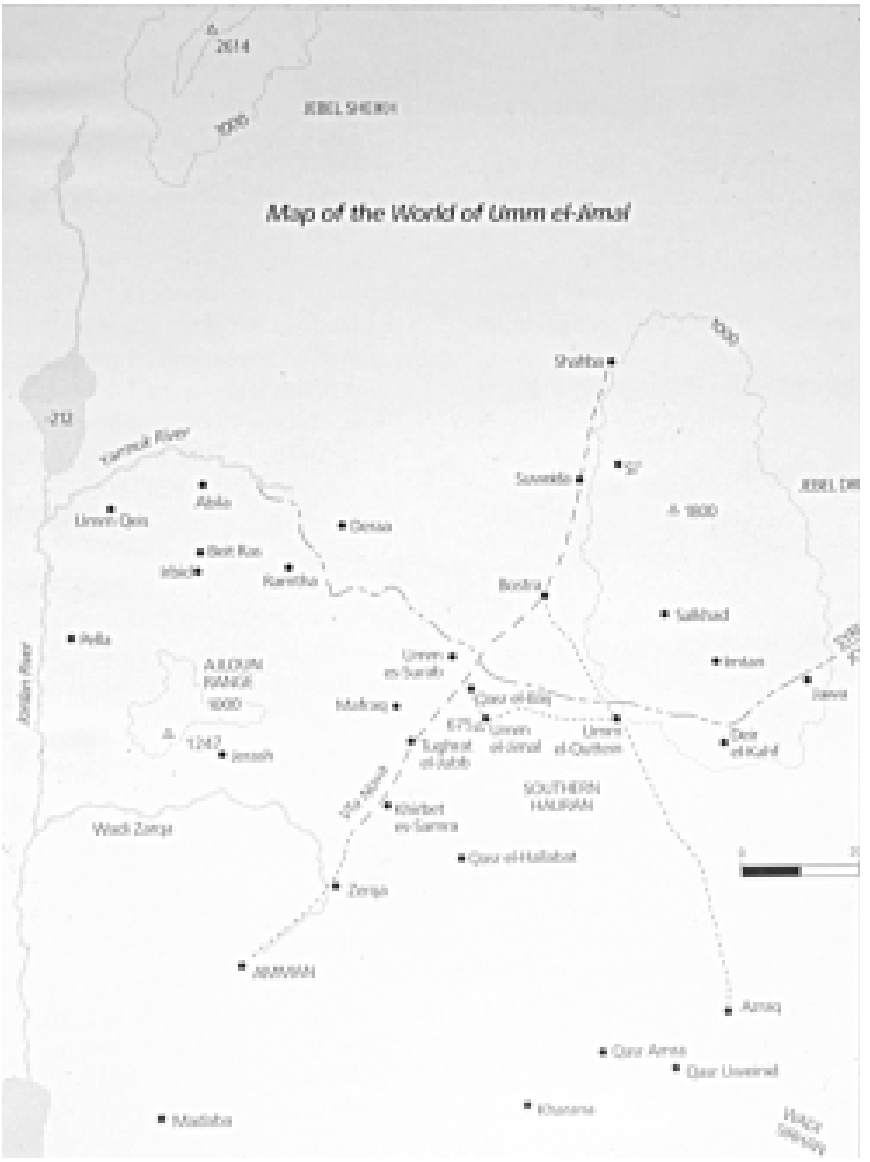

Figura 13: Ruta caravanera por Haurán,, B. de Vries, "What's in a Name: The Anonymity of Ancient Umm el-Jimal", Biblical Archaeologist, 57:4, 1994, p. 217.

lación del espacio usado en la construcción de las iglesias, sigue los modos de la arquitectura tradicional de las viviendas privadas, lo que he llamado, "la fuerza de lo vernáculo en la arquitectura religiosa".

Las formas arquitectónicas en el Medio Oriente tienen una milenaria historia. Muestran un estrecho vínculo con una forma tradicional de pensamiento, con un cierto modo de sentir lo religioso y la cosmología; reflejan las formas de vida, las jerarquías familiares y sociales. Se desarrollan en armonía con el entorno natural, con el clima, con los materiales de cada región.

En el Medio Oriente la construcción del espacio religioso propio de las comunidades cristianas está estrechamente vinculado con vivencias y con un sentir espiritual de raíces muy profundas. La arquitectura de cada región tiene claros rasgos identitarios y va reflejando, de comunidad en comunidad, los diferentes matices, los distintos ritos y modos con que los fieles vivieron y expresaron sus creencias.

En algunos casos, como me parece sucedió en el Medio Oriente, el control central fuerte y totalitario que ejerció el Imperio en las áreas bajo su hegemonía, impulsó a las culturas tradicionales hacia un reforzamiento de su propia identidad, 
como una manera de expresar su rechazo a este poder hegemónico. Esta idea adquiere una mayor fuerza, si estamos ante culturas en donde el componente tribal es muy fuerte. Es propio de esta estructura social, tan característica hasta el día de hoy en la región del Medio Oriente, que las comunidades estén acostumbradas a los liderazgos de los jefes locales y tribales y no acepten ni entiendan cualquier intento de ejercer un poder central totalizante.

Para el estudio de la arquitectura del Haurán, he logrado recopilar un corpus de 34 iglesias con sus plantas bien conservadas. Del intento de ubicar cada una de estas iglesias en un lugar geográfico preciso, se ha configurado el grupo de comunidades de la meseta del Haurán (ver Fig. 12).

Con bastante dificultad, debido a la gran variedad de tipos de iglesias, he intentado ordenar estas plantas según sus rasgos más distintivos: número de naves, dirección de los arcos, calidad del techo, característica de los ábsides (ver Figs. 14, 15,16 y 17).

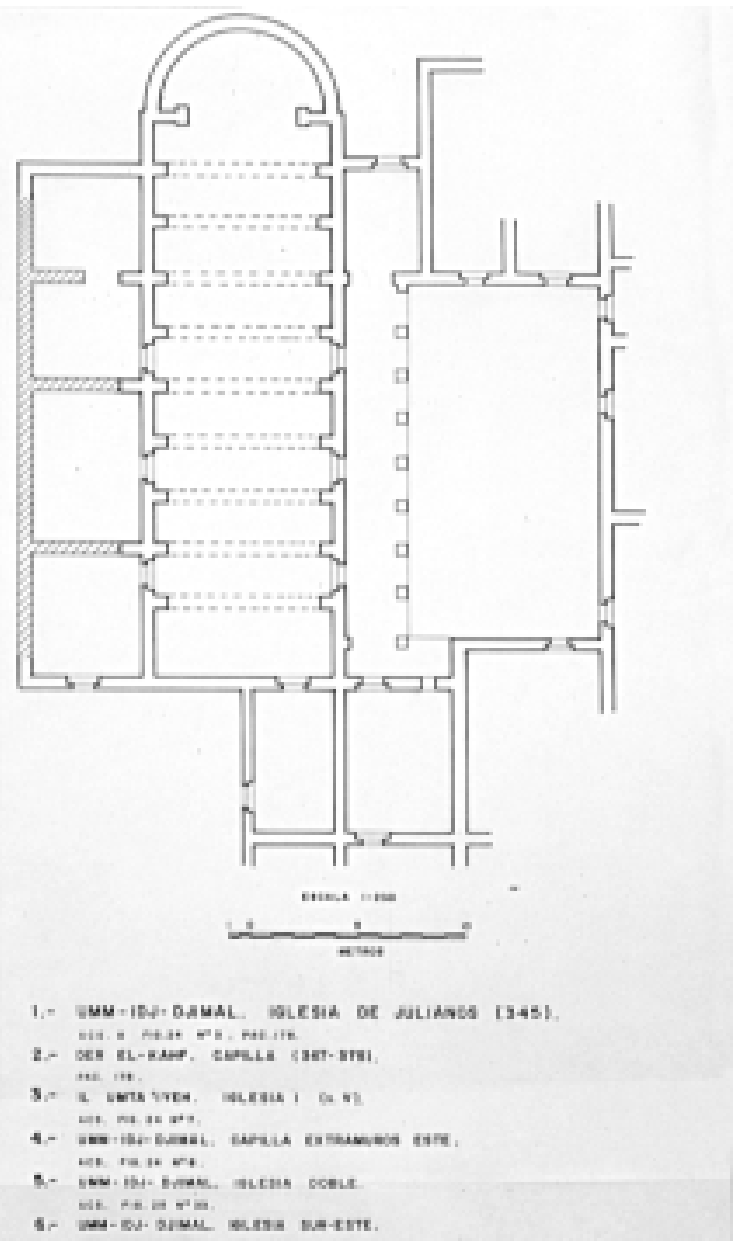

Figura 14: Iglesias del Haurán con una nave, arcos transversales y ábside exento, M. T. Viviani, Semiótica y Estética: Arquitectura Cristiana Mesoriental (S. I-V), Tesis de Grado, P. Universidad Católica de Chile, 1987. Abreviaturas: ACS, J. Strzygowski. L'Ancient Art Chrétienne de Syrie, E. de Boccard, Paris, 1936. PAC, A. Grabar, El primer arte cristiano, Aguilar, Madrid, 1967. 


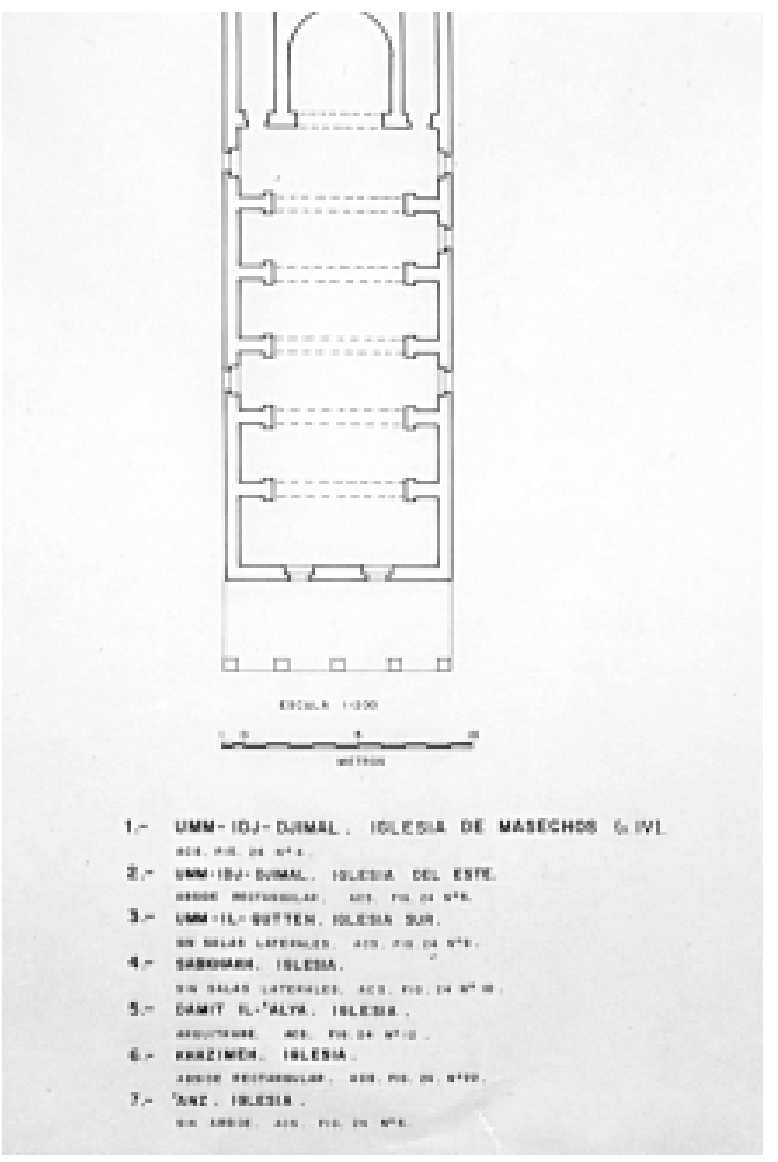

Figura 15: Iglesias del Haurán con una nave, arcos transversales, ábside interno y dos habitaciones laterales, M. T. Viviani, Semiótica y Estética: Arquitectura Cristiana Mesoriental (S. I-V), Tesis de Grado, P. Universidad Católica de Chile, 1987.

La mayoría de las iglesias reflejan un estrecho vínculo con la arquitectura de las viviendas y edificios civiles de la zona. Lo más llamativo y distintivo es el techo, construido con enormes losas de piedra volcánica de basalto, de aproximadamente tres metros cada una, soportadas por reforzados arcos y pilastras. El "Desierto Negro" proveía las losas y los materiales de construcción y estas losas, a su vez, protegían a sus usuarios del sofocante calor de la zona. Se generaba un microclima fresco y sombrío, como de invernadero, semejante al del las celdas que construían los monjes en los acantilados de los cerros (ver Figs. 18 y 19).

Las enormes piedras de tres metros cada una y los arcos que las soportaban, generaban un espacio modular que va progresando rítmicamente de tres en tres, sugiriendo movimiento y un permanente desplazamiento. Esta sensación de avance se ve reforzada por las naves muy angostas y largas y los ábsides muy profundos. Es un espacio para pasar a través, más que para permanecer en él.

Lo más notable de la arquitectura cristiana de la zona, y que no encontramos en otra región del universo cristiano de la época, es un grupo de iglesias de una sola 


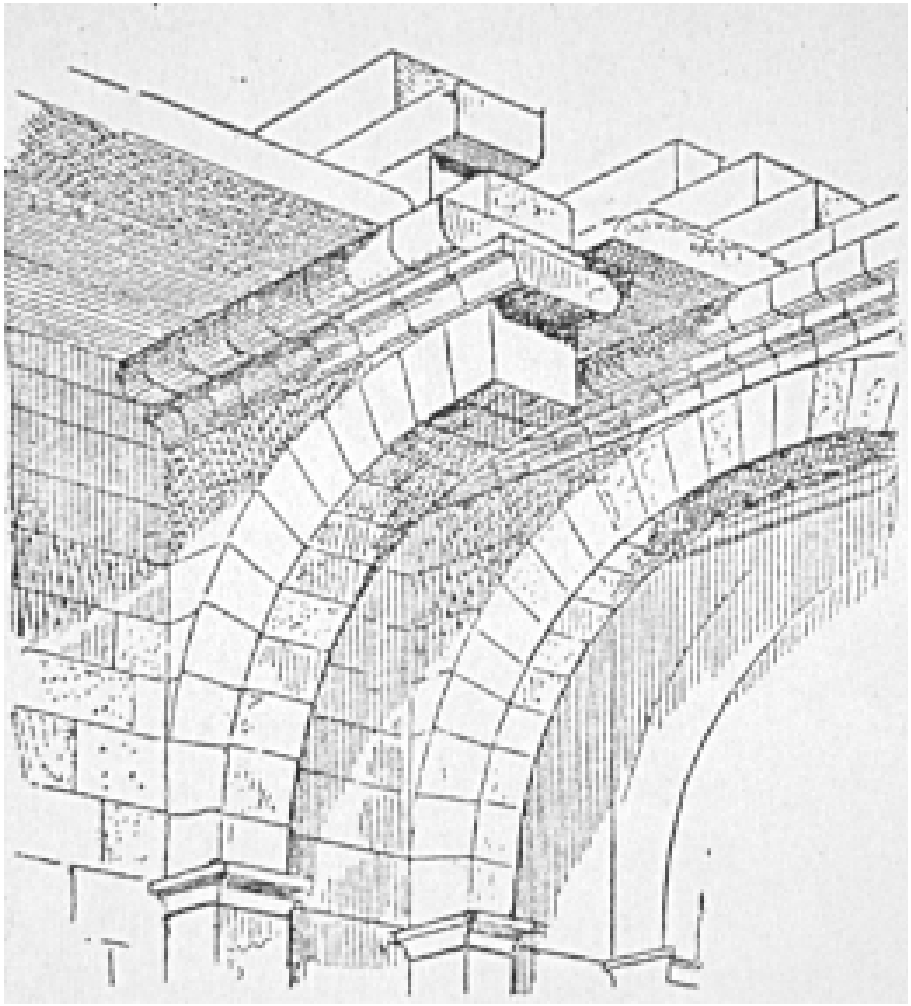

Figura 18: Técnica de construcción de techo de piedra, J. Strzygowski, L'Ancient Art Chrétienne de Syrie, E. de Boccard, Paris, 1936, p. 44.

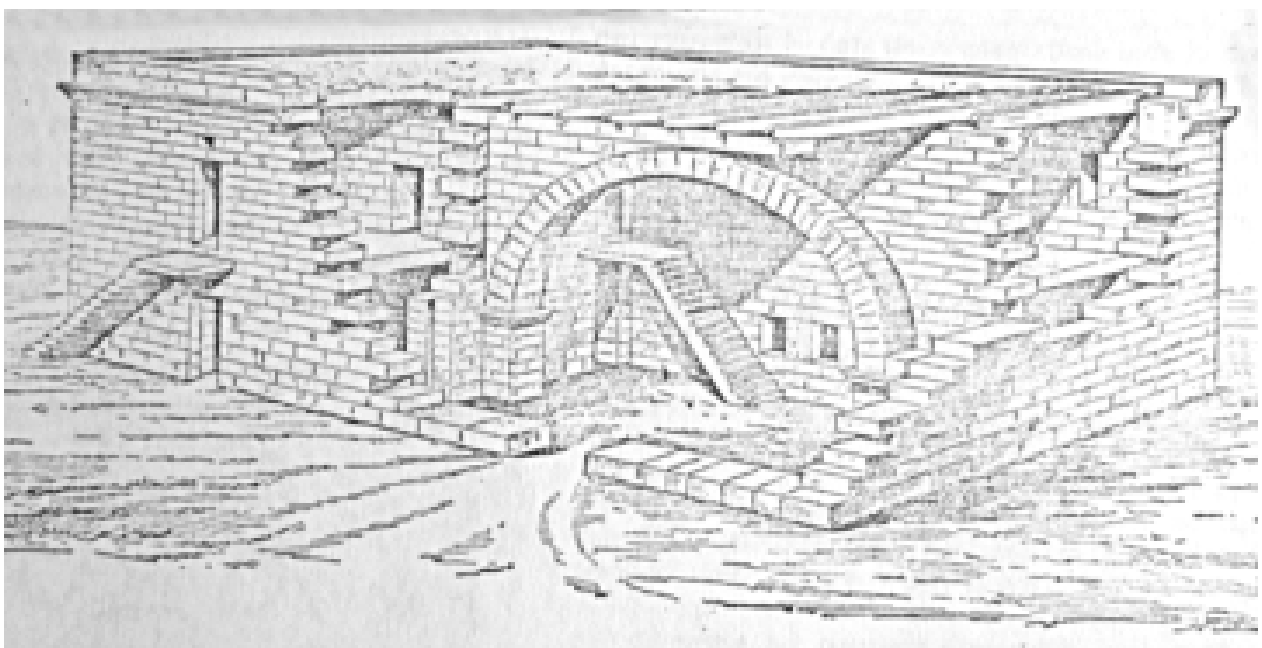

Figura 19: Vivienda del Haurán con techo de piedra, Douma, H. Leclerq, Manuel d'Archeólogie Chrétienne, Tome Second, Paris, 1907, p. 52. 
nave, muy angosta, muy larga, con rítmicos arcos transversales y ábsides muy profundos y amplios.

Estas iglesias sugieren un ritual procesional, o bien, un acomodarse en círculos sentados en el suelo, como acostumbran hacerlo aún hoy los pueblos nómades beduinos de la región. Las iglesias reproducen las estructuras alargadas de las tiendas beduinas, hechas con materiales vegetales o con paños tejidos, rítmicamente articuladas con contrafuertes y planos rehundidos. Reflejan también el permanente movimiento de la vida de transhumancia (ver Figs. 20 y 21).

Sugiero, solo a modo de hipótesis, ya que no tengo suficiente documentación como para poder probarlo, que estos espacio alargados, además de ser usados para sentarse en círculos, servían a fines procesionales. Algunos documentos de Jerusalén informan de monjes de la Transjordania que llegaban en busca de aceite consagrado, necesario para sus ritos. Otras fuentes sugieren que algunos grupos monofisitas reemplazaban el rito eucarístico de pan y vino por el de unción de aceite.

Considerando estos datos, la abundante población monofisita de la zona, las características de las naves de las iglesias y de los ábsides tan amplios y profundos, me parece funcional pensar que, a lo mejor, estos espacios servían a algún rito procesional con estos fines de unción de aceite. Es solo una idea y estoy intentando recopilar más información sobre el tema.

Todas las iglesias del Haurán usan el arco, el ábside, y están orientadas hacia el este, lugar del sol naciente; todos elementos de claro referente cosmológico.

Se cree que el reiterado y simbólico uso del arco en la arquitectura cristiana es originario de esta región y desde aquí comenzaría a expandirse hacia occidente. Los

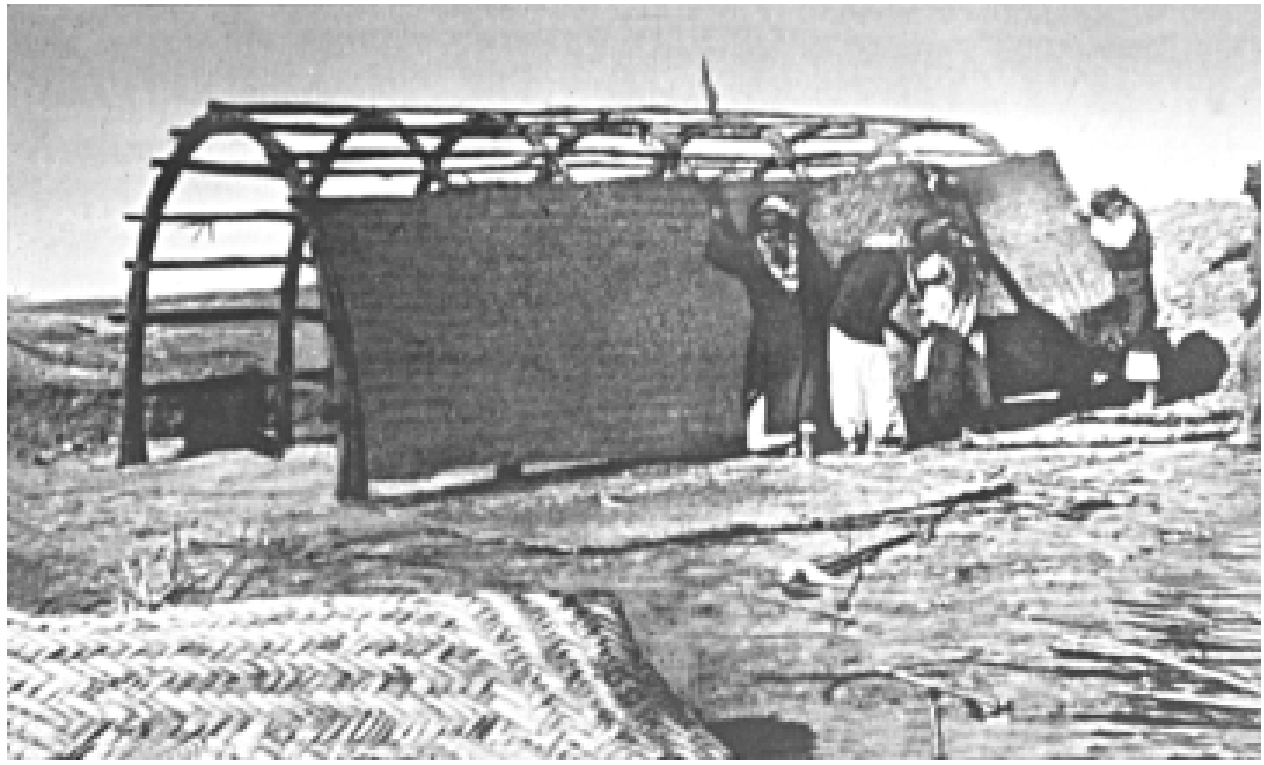

Figura 20: Construcción de vivienda con fibra vegetal, contrafuertes y tejidos lisos que generan ritmos como en las iglesias de piedra, Mesopotamia. 


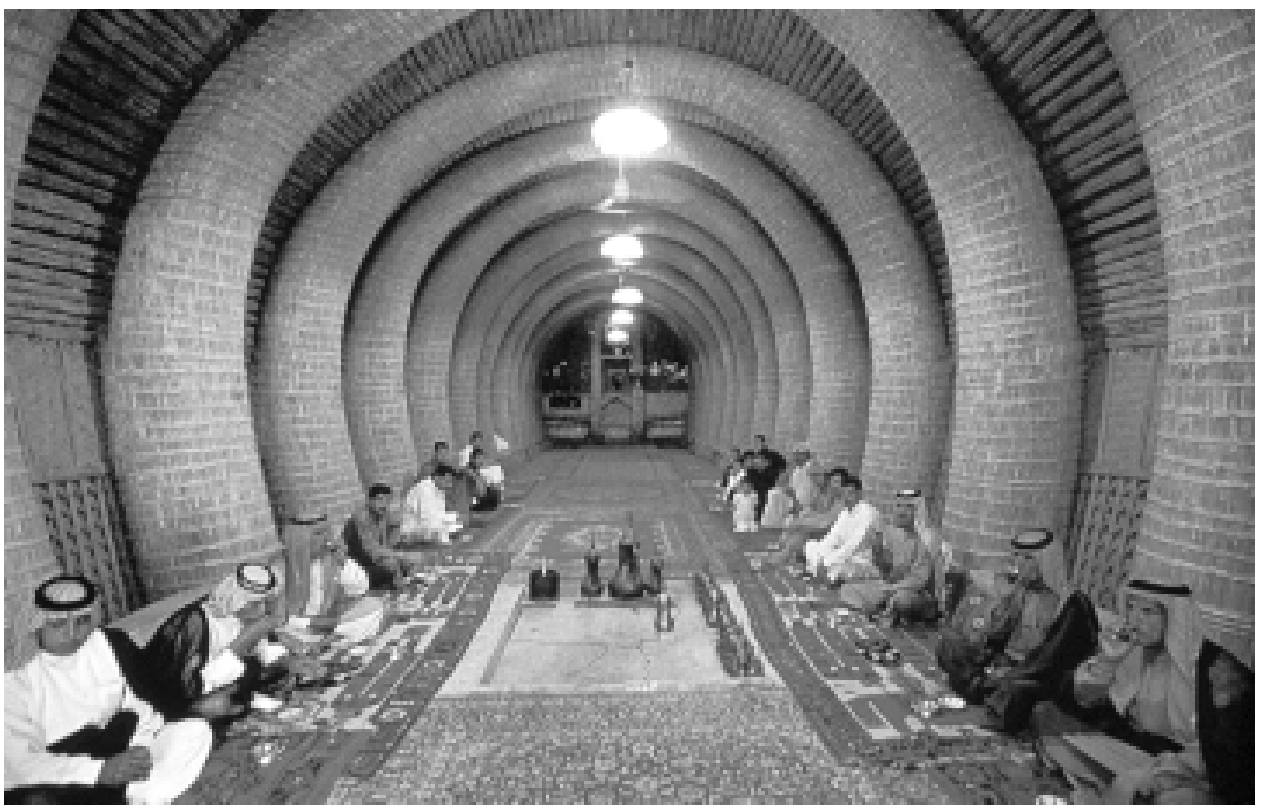

Figura 21: Vivienda tradicional con fibra vegetal, contrafuertes y muros lisos, Irak, The National Geographic, 2/13, May 2001.

romanos terminarán utilizándolo en las basílicas, en lugar del arquitrabe recto, propio de la arquitectura griega y romana. Un edificio público romano en Mousmiyé (160-164 D. C.) y una basílica civil romana, en Transjordania, testimonian en una fecha muy temprana el uso por parte de los romanos, del arco propio del Haurán (ver Figs. 22 y 23).

Las iglesias del Haurán son muy pequeñas y muy numerosas. Por lo general, no tienen más de $10 \mathrm{~m}$ de frente. Como dice Bert De Vries, un muy buen estudioso de la zona, solo sirven a los intereses de los vecinos del barrio. Si en las grandes ciudades son visibles una o dos basílicas, aquí, cada aldea tiene una docena o más (25).

Las características domésticas de las iglesias y el modo como se mimetizan y se insertan en medio de las viviendas, hace recordar la "Casa Cristiana" o "Iglesia Doméstica" de los primeros siglos (26). Es como si el espacio privado, con todo su peso y tradición, emergiera en el espacio público, pero manteniendo su sentido de intimidad y familiaridad (ver Fig. 24).

Un testimonio muy elocuente de Eusebio de Cesarea hace alusión a las pequeñas dimensiónes de las iglesias de oriente:

(25) B. de Vries, "Jordan's Churches. Their Urban Context in Late Antiquity", Biblical Archaeologist, December (1988), pp. 229-237. "What's in a Name: The Anonymity of Ancient Umm el-Jimal", Biblical Archaeologist, 57:4 (1994), pp. 215-219.

(26) Ver cita 18. 


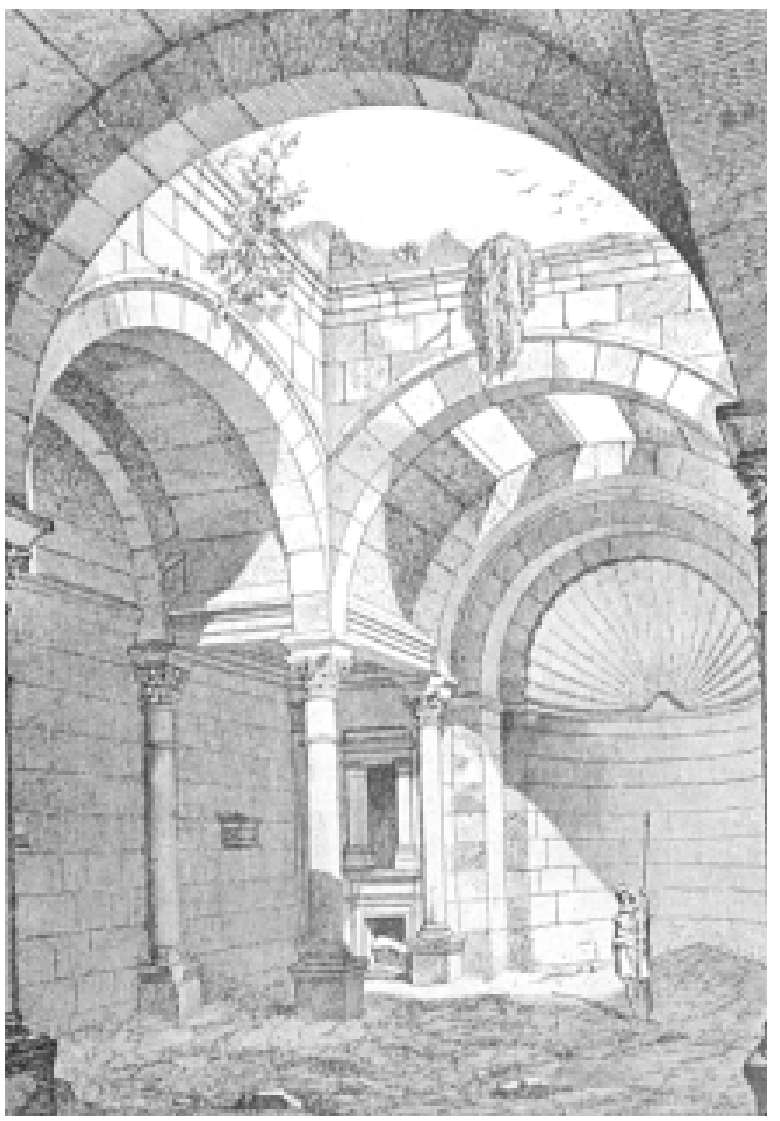

Figura 22: Pretorio Romano (160-169 D. C.), techo con losas de piedra y arcos, Mousmiyé, Haurán, ACS, p. 187.

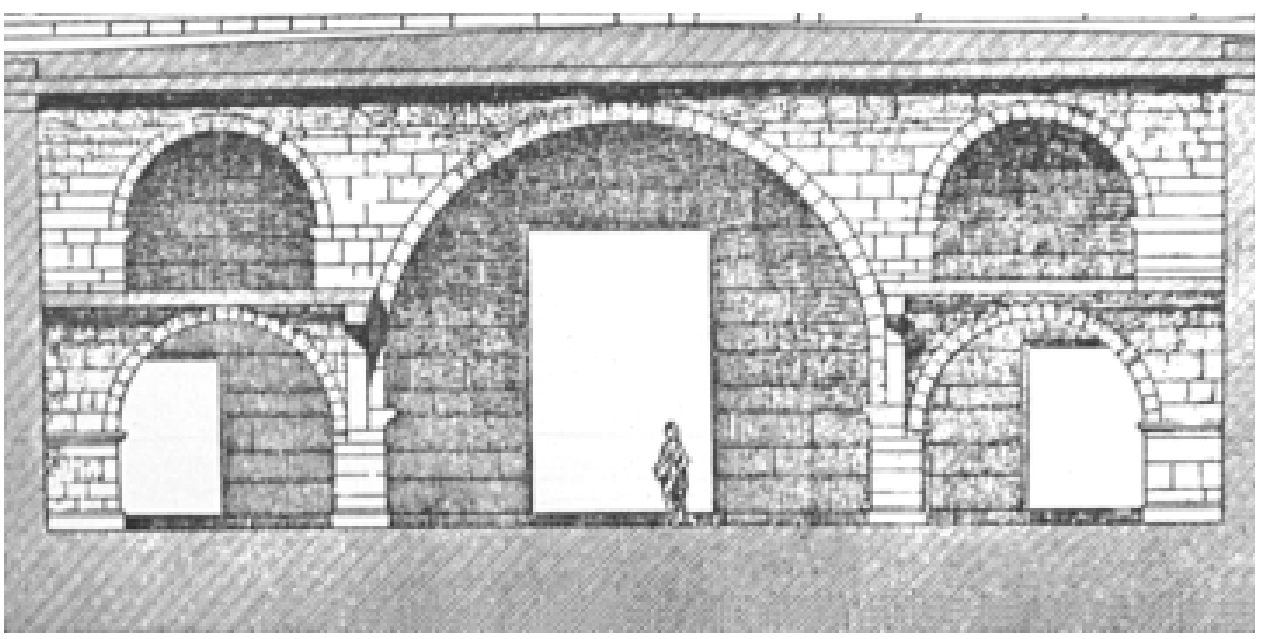

Figura 23: Basílica Romana, edificio público, techo con losas de piedra y arcos, Chakka, Haurán, ACS. 


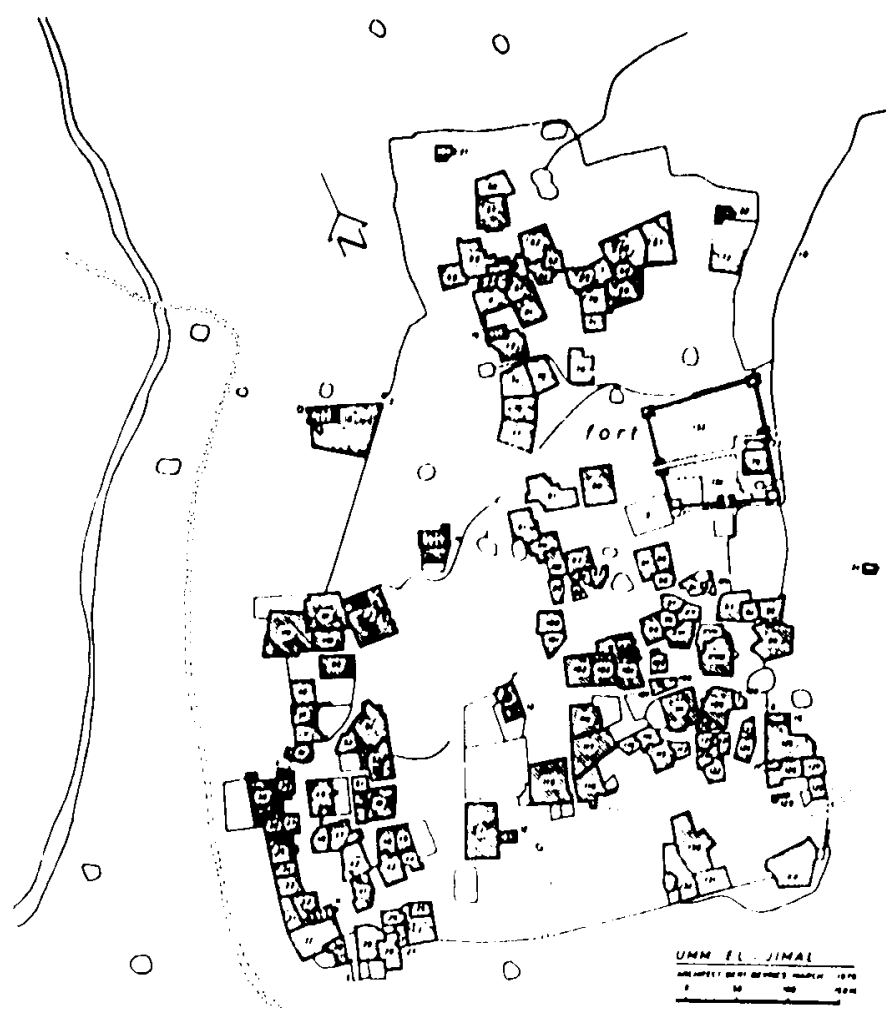

Figura 24: Plan of Umm al-Jimal (after de Vries), D. Whitcomb, "Amsar in Syria? Syrian cities after the conquest", ARAM, 6 (1994), p. 32.

“... se publicaron dos leyes: una poniendo veto a los abominables ritos de la antigua idolatría... La otra, mandando a las iglesias de Dios que aumentaran las dimensiones de sus templos en altura, anchura y longitud, como si se esperara que todos los hombres, por así decirlo, se vincularan estrechamente a Dios" (27).

Está claro que las iglesias de oriente no seguían las normas establecidas por el propio Emperador y por Eusebio para la construcción del Santo Sepulcro, que tenía que servir de modelo a toda futura basílica. Debía ser el lugar más admirable del universo y derrotar a todo otro edificio por su eximia belleza. Sobre este tema, el Emperador manda las siguientes instrucciones a Eusebio:

"Es preciso, en consecuencia, que tu solicitud disponga y provea de toda cosa necesaria, de tal modo que la basílica no solo resulte mejor que las de otro sitio, sino también las restantes partes del conjunto se configuren de tal manera que todo lo que pueda haber de eximia belleza en cualesquiera urbe, sea derro-

(27) Eusebio de Cesarea, Vida de Constantino, Libro II, 45, Gredos, Madrid, 1994, p. 237. 
tado en parangón con esta construcción... Por lo que toca a las columnas y los mármoles, que a tu juicio sean los más apreciados y útiles, y una vez que los hayas examinado en persona, date prisa en escribirnos, para que puedan ser transportados desde cualquier punto...; pues justo es que el lugar más admirable del universo descuelle por su ornato como se merece" (28).

Muchas comunidades deben haber participado con mucho asombro de la construcción de este edificio y posiblemente, otras tantas, no aprobaron que un monumento que servía a fines imperiales, se usara ahora para una iglesia cristiana. La construcción del Santo Sepulcro significó un quiebre radical con la antigua tradición de la "Casa Cristiana" (29).

Las iglesias del Hauran, como ya lo hemos dicho, no siguen un modelo fijo. Hay iglesias de una o tres naves, con ábsides inscritos o exentos. En algunos casos los arcos están puestos transversalmente y en otros longitudinalmente. Algunas tienen techo de piedra, y otras, de madera a dos aguas como las basílicas. Hay iglesias que tienen el ábside en forma de herradura y con tres ventanas, lo que es propio de las iglesias de Capadocia (ver Figs. 25 y 26).

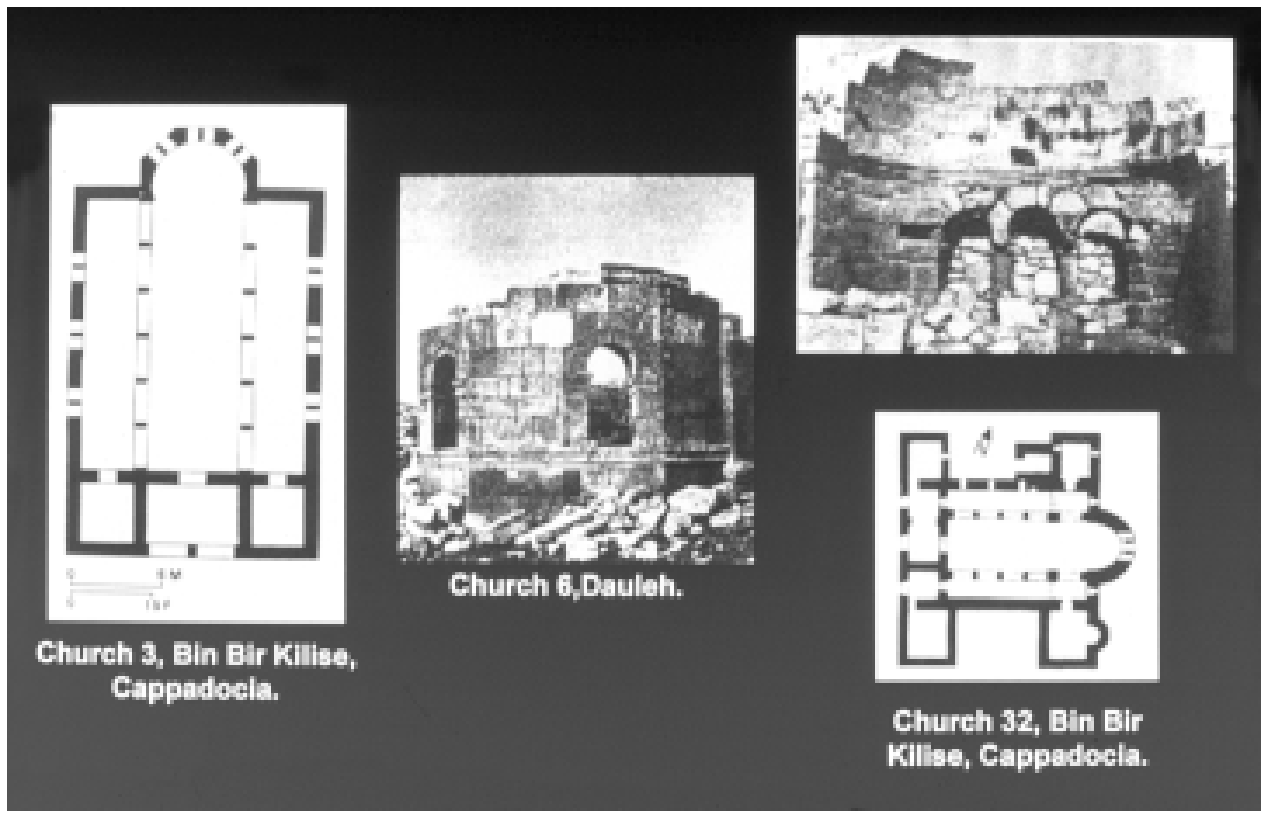

Figura 25: Iglesias en Capadocia. Church 3, A. Grabar, La Edad de Oro de Justiniano, Aguilar, Madrid, 1975, p. 360. Church 32, R. Krautheimer, Arquitectura Paleocristiana y Bizantina, Cátedra, Madrid, 1984, p. 192.

(28) Eusebio de Cesarea, Vida de Constantino, Libro III, 31-32, Gredos, Madrid, 1994, p. 294

(29) Ver cita 18 


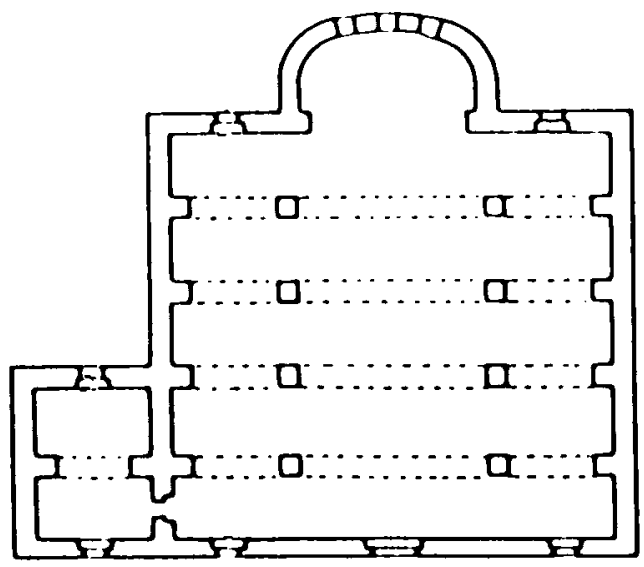

Figura 26: Iglesia con tres ventanas en el ábside y arco de herradura.

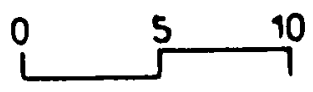

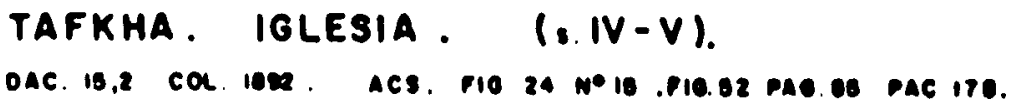

La enorme variedad de modelos, algunos llegados desde distintos y lejanos lugares del universo cristiano, posiblemente obedecía al asilo y refugio que las comunidades dieron a tantos fieles. Cada cual se integraba a la nueva vida comunitaria, pero algo traía consigo de su propia identidad y modo religioso. En términos muy actuales, es lo que llamaríamos una multicultura.

Esta gran variedad de iglesias nos habla de comunidades en donde el rito y la celebración es más fuerte que el predominio de un dogma o doctrina oficial. La arquitectura religiosa del Hauran nos testimonia el alto grado de libertad y tolerancia de sus comunidades. Todo nos lleva a pensar que cada pequeño grupo podía seguir sus propios ritos y costumbres, sin llegar a desperfilarse por esta razón los rasgos comunes que las identifican como cristianas. Estas características comunes, orientación hacia el este, gran nave central para el uso de la comunidad, el uso del arco y del ábside, recorren invariablemente toda la arquitectura cristiana de los primeros siglos.

Se ha estudiado poco el sentido profundo de estos símbolos que unifican el cristianismo de los primeros siglos, más allá de las múltiples variantes regionales. Es un tema interesante y que podría entregar luces a las inquietudes ecuménicas de nuestro tiempo.

Los monjes y anacoretas desempeñaron una especial misión evangelizadora en las comunidades del Hauran. Se acercaban a las aldeas o ciudades, se ganaban la simpatía de la población y empezaban a enseñar. Cuando ya habían formado una nueva comunidad, construían una iglesia y se perdían nuevamente en el desierto. 
Vööbus dice:

"Para la masa religiosa ellos eran una garantía para la sociedad; mantenían apartadas tanto las catástrofes como las calamidades. Esta es la razón por la cual en las fuentes, una y otra vez, encontramos la misma historia con variaciones: Cuando los habitantes de una aldea o comunidad se informaban de la llegada de un monje a la vecindad, amablemente le ofrecían ayuda para construir su celda como manera de retenerlos con ellos" (30).

El autor también nos cuenta que algunos monjes tenían tanto prestigio, que se emprendían verdaderas persecuciones en el desierto para obligarlos a ser obispos. Esto aseguraba la tranquilidad del grupo y el respeto por las reliquias de los mártires.

El estudio del cristianismo Nabateo de los primeros siglos no es fácil, ya que en cuanto a escritura solo disponemos de inscripciones Nabateas o de información sobre ellos que proviene de fuentes no Nabateas. Hoy se está estudiando el desarrollo de la escritura en estos pueblos y la relación entre la escritura y la oralidad, pero es un tema muy complejo y amplio como para ser abordado en este trabajo.

La mayoría de los textos considerados árabes son textos tardíos, posteriores al siglo VI D. C., y provienen en gran parte de traducciones de textos griegos, coptos o siríacos. Muchas de estas traducciones fueron realizadas en pleno período de ocupación musulmana.

\section{D) Pastores y Caravaneros}

Mayoritariamente, las comunidades cristianas del este del Jordán eran de origen Nabateo. Era un pueblo nómade dedicado al pastoreo y al comercio de las caravanas. Con el tiempo llegaron a construir elaborados sistemas de riego, a veces con la ayuda de los romanos, lo que les permitió desarrollar la agricultura y sedentarizarse, dando origen a las aldeas del Haurán que ya hemos analizado (31); entre ellos encontramos formas nómades de cristianismo.

No se sabe mucho de la proveniencia de los Nabateos, pero se tiende a separarlos de los Arameos, que posiblemente provienen del norte. Se los vincula más con los pueblos Edomitas o pueblos de la Península de Arabia. De hecho, siempre mantuvieron mayores relaciones con las poblaciones del sur que con las tribus del norte y de Siria, con quienes mantenían cierta rivalidad. No hay que confundirlos con las comunidades cristianas que viven al interior de Siria.

Los Nabateos instalaron su capital en Petra, lugar estratégico tanto para la defensa, como para el control de las caravanas que provenían del sur de Mesopotamia, de la India, de Arabia y del Mediterráneo. Se los conoció como los guardianes del desierto.

Por el norte, en su tráfico caravanero, los Nabateos llegaban hasta Palmira, y por el sur, penetraban hasta Arabia y el Yemen. En ciertas épocas del año cruzaban hacia

(30) A. Vööbus, "History of Ascetism in the Syrian Orient", t. II, Corpus Scriptorum Christianorum Orientalium, vol. 197, Secretariat du Corpus SCO, Louvain, 196O, p. 324.

(31) Sobre los Nabateos, ver "The Nabataeans", ARAM Periodical, 2: 1 y 2 (1990), Oxford. 
Palestina por el sur del Desierto del Negev, en zonas con lluvias inferiores a los 200 $\mathrm{mm}$, que solo eran útiles para el pastoreo y que no interesaban a los romanos (32).

Las ciudades de Oboda, Elusa y Mampsis, en el Sur de Palestina, son de origen Nabateo y fueron ocupadas por ellos hasta el S. III D. C. Posteriormente, fueron ocupadas por los romanos, que las fortificaron y construyeron en ellas numerosas basílicas cristianas, posiblemente para la población militar de las guarniciones. Se podría decir que esta fue la frontera real que marcó los límites del control permanente romano. Esto no significa que, por momentos, los romanos no llegaran hasta Petra, e incluso penetraran en Arabia (ver Fig. 27).

Los Nabateos se cristianizaron muy tempranamente. En las Actas de los Apóstoles y en las Epístolas de Pablo se nombra ya a los árabes. Se sabe que Orígenes viajó a la zona árabe para dirimir disputas teológicas y que a comienzos del S. IV,

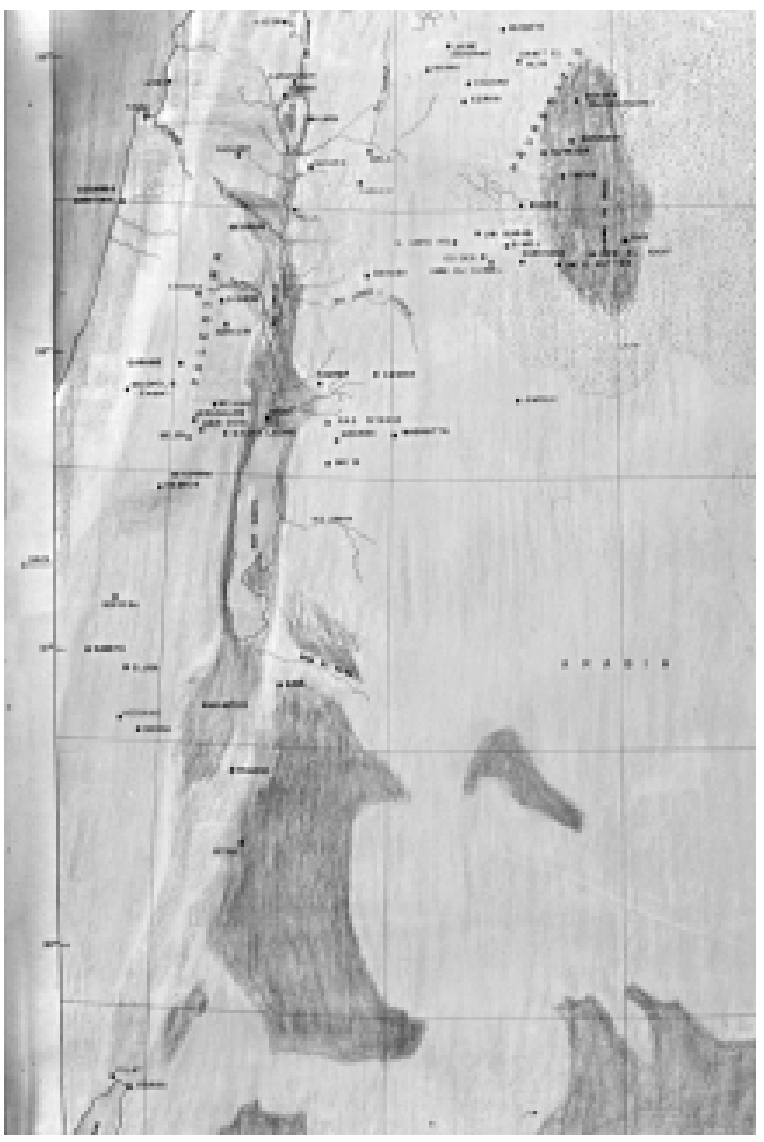

Figura 27: Palestina y Transjordania, sitios con plantas de iglesias. Mampsis, Oboda y Elusa, al sur de Palestina, aldeas de origen Nabateo.

(32) Sobre pastores nómades en el Negev, ver Steven A. Rosen y Gideon Avni, "The Edge of the Empire: The Archaeology of Pastoral Nomads in the Southern Negev Highlands in Late Antiquity", Biblical Archaeologist, 56,4 (December 1993), pp. 189-198. 
según testimonios de Eusebio de Cesarea, obispos árabes participaron en el Segundo Sínodo de Jerusalén.

A. Vööbus (33) nos cuenta de tiendas beduinas que servían de iglesia y de obispos beduinos. Eran grandes admiradores de los monjes, especialmente de los estilitas y peregrinaban hasta Siria para visitar a San Simeón Estilita, el famoso monje que vivió 30 años sobre una columna. Este era el principal lugar de peregrinación de la zona, más importante que Jerusalén o los lugares santos de Palestina. Tiene que haber sido muy impresionante para un pueblo acostumbrado al permanente nomadismo encontrarse con estos santos que pasaban su vida sobre una columna (ver Fig.28).

Los Láchmidas de Hira, que controlaron el este del Jordán desde la caída de Palmira (272 D. C.), se cristianizaron en el S. IV. Tienen sus propios obispos en el año 410. Cerca de Hira se construyeron muchos monasterios nestorianos y monofisitas. Las mujeres cumplieron un importante rol en la fundación de monasterios, al igual que en Palestina.

Los Ghassánidas, tribus que suceden en el control de la región a los Láchmidas, se transformaron en los protectores de los monofisitas y de la gran cantidad de

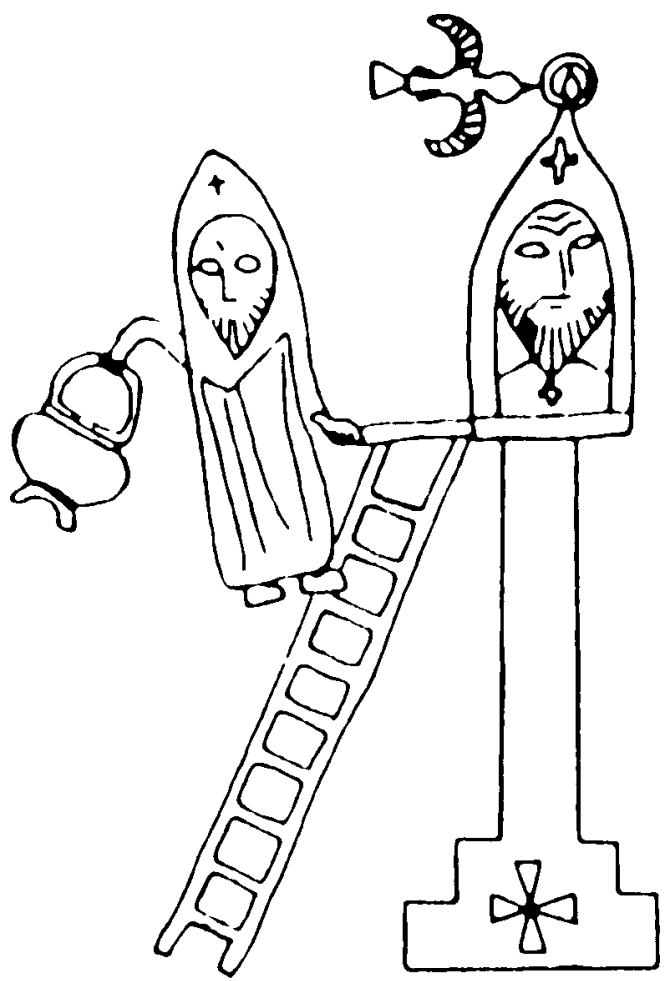

Figura 28: San Simeón Estilita (386-459 D. C.) atendido por un monje, bajo relieve en basalto (S. VI), Qasr Abou-Samra, DAC., 15,2, col. 1916. 
monasterios de la región. Arith Bar Gabala viaja a Constantinopla para solicitar un obispo de lengua árabe para la población árabe. Cuenta con el apoyo de Theodora, mujer de Justiniano, y logra se nombre a Theodoro de Arabia obispo para la región. Theodoro tuvo su sede en Bosra, pero se dice que vivió entre las comunidades del Haurán (34).

Años más tarde, Mundir, hijo de Bar Gabala, reclama por las persecuciones a que están siendo sometidos los cristianos monofisitas.

A través del movimiento de los pueblos pastores y del comercio de las caravanas, el cristianismo penetró en Arabia, en el Yemen y en el sur de Mesopotamia. Mantuvieron también estrecha relación con los cristianos coptos de Egipto.

Cuando los musulmanes ocupan Transjordania, las comunidades cristianas familiarizadas con el trato de las tribus de Arabia, continuaron viviendo en la región sin grandes cambios. Se sabe de grupos cristianos Ghassánidas que lucharon al lado de los musulmanes contra el poder que representaba al Imperio Romano.

El ejército romano de Heraclio fue derrotado por los musulmanes en el Jordán, en el Wadi Yarmuk, el año 636 D. C., después de lo cual los romanos debieron abandonar definitivamente el Medio Oriente y el territorio del Imperio quedó reducido a la península de Anatolia. Damasco se transformó en la capital del Califato Omeya y fue el gran centro intelectual de encuentro entre las comunidades cristianas y el Islam. Por mucho tiempo y en pleno período de dominio musulmán su población continuó siendo mayoritariamente cristiana. La región de la Transjordania pasó a ser un lugar de primera importancia para el Islam, por ser una importante ruta para las peregrinaciones al santuario de la Kaabah en Arabia (35).

\section{RESUMEN}

Este estudio analiza, a través de la forma arquitectónica, las comunidades cristianas que vivieron al este del Jordán. El río desciende por una falla geológica, el Gran Rift, que actuó como barrera natural, separando las comunidades del este y del oeste.

La principal actividad de la región es el comercio caravanero, lo que significa un flujo permanente de población y de influencias culturales.

Desde la perspectiva occidental, las tierras del este adquieren una carga histórica negativa. La Transjordania solo se ve desde lejos y todo lo "nefasto" acontece al otro lado del río. Los romanos no controlaron la zona y pactaron con las tribus locales la defensa de las fronteras con los persas.

Se estudian cuatro tipos de comunidades: a) Las ciudades de la Decápolis claramente romanizadas. Son de origen nabateo, helenizadas por los ptolomeos y luego por los seléucidas. b) Los monjes que viven en el flanco del río, de preferencia cerca de Perea y el Monte Nebo. c) Las comunidades del Haurán, meseta volcánica llamada "Desierto Negro". Lo notable de esta arquitectura, es la relación con la arquitectura vernácula y la ausencia de la característica basílica romana. Las iglesias no siguen un modelo fijo y encontramos edificios

(34) I. Shaid, "The restoration of the Ghassanid dynasty", ARAM Periodical, 5 (1993), Oxford, pp. 491-503.

(35) H. Kennedy, "Change and Continuity in Syria and Palestine at the time of the Moslem Conquest", ARAM periodical, 1:2 (1989), Oxford. Ahmad Shboul, "Change and continuity in early Islamic Damascus". ARAM Periodical, 6 (1994), pp. 67-102. 
de distintas regiones del universo cristiano. d) Pastores y caravaneros. Las mayoría de las comunidades eran de origen nabateo, pueblo mayoritariamente nómade. Encontramos entre esta población formas beduinas de cristianismo. El monofisismo era la forma predominante de cristianismo.

\begin{abstract}
This study analyses the Christian communities that lived at the east of the Jordan river through their architectonic forms. The river descends by a geological fault, the Grand Rift, which worked as a natural barrier that separated the East and West communities. The main activity of the region is the caravan trade that implies a constant affluent of people and cultural influences.

From the western perspective, the territories of the East acquired a negative historic burden. The Transjordan region is only perceived from a distance and all the 'wretchedness' happened on the other side of the river. The Romans did not controlled the area and negotiated the defense of the border lines with the Persians.

Four types of communities are studied: a) the Decapolis cities, of Nabatean origin and hellenized by the Ptolomeans and the Seleucids, present a clear Roman influence; b) the monks that live by the river side, mostly near the Perea and Mount Nebo; c) the communities of the Hawran, a volcanic plateau called 'Black Desert'. It is relevant concerning this architectural form its connection to the vernacular architecture and the total abscence in this area of the distinctive Roman Basilica. The churches do not follow a fixed pattern and we find buildings representative from different regions of the Christian world; d) Shepherds and caravaners. Most communities were of Nabatean origin, a mainly nomad tribe. We find Bedouin forms of Christianity among this population. The monophysism was the predominant Christian form.
\end{abstract}

